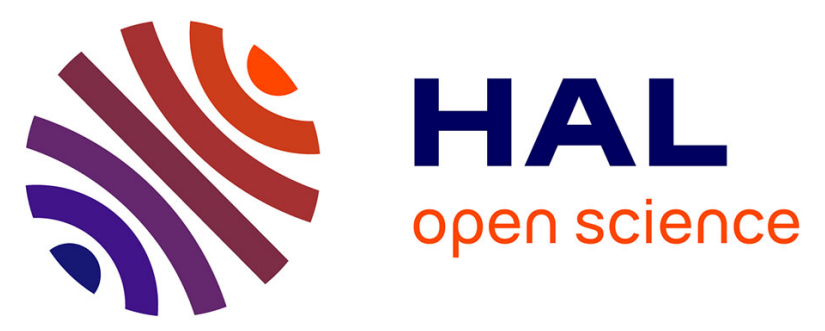

\title{
Corrosion analysis of AISI 430 stainless steel in the presence of Escherichia coli and Staphylococcus aureus
}

Carolina Guerra, A. Ringuedé, M.I. I Azocar, M. Walter, C. Galarce, F. Bedioui, M. Cassir, Mamié Sancy

\section{- To cite this version:}

Carolina Guerra, A. Ringuedé, M.I. I Azocar, M. Walter, C. Galarce, et al.. Corrosion analysis of AISI 430 stainless steel in the presence of Escherichia coli and Staphylococcus aureus. Corrosion Science, 2021, 181, pp.109204. 10.1016/j.corsci.2020.109204 . hal-03412688

\section{HAL Id: hal-03412688 \\ https://hal.science/hal-03412688}

Submitted on 3 Nov 2021

HAL is a multi-disciplinary open access archive for the deposit and dissemination of scientific research documents, whether they are published or not. The documents may come from teaching and research institutions in France or abroad, or from public or private research centers.
L'archive ouverte pluridisciplinaire HAL, est destinée au dépôt et à la diffusion de documents scientifiques de niveau recherche, publiés ou non, émanant des établissements d'enseignement et de recherche français ou étrangers, des laboratoires publics ou privés. 


\section{Corrosion Analysis of AISI 430 Stainless Steel in the presence of Escherichia coli and Staphylococcus aureus}

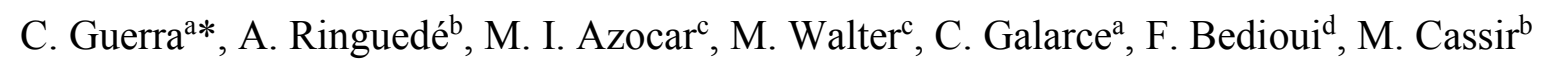
and M. Sancy,e*

*Corresponding authors: Carolina Guerra and Mamié Sancy e-mail: caguerra2@uc.cl/mamiesancy@gmail.com

Tel: + 5622354 7084/+ 56223547908

${ }^{a}$ Facultad de Ingeniería, Pontificia Universidad Católica de Chile, Vicuña Mackenna 4860, Santiago, Chile.

${ }^{\mathrm{b}}$ Chimie ParisTech, PSL Research University, CNRS, Institut de Recherche de Chimie de Paris, F-75231 Paris Cedex 05, France. 'Facultad de Química y Biología, Universidad de Santiago de Chile, Alameda 3363, Santiago, Chile.

${ }^{\mathrm{d}}$ Chimie ParisTech, PSL Research University, CNRS 2027, Institute of Chemistry for Health and Life Science, 75005 Paris, France.

'CIEN-UC", Pontificia Universidad Católica de Chile, Vicuña Mackenna 4860, Santiago, Chile.

\section{Abstract}

AISI 430 stainless steel is an attractive material to be used in the healthcare industry, particularly as a sensor due to its low cost, corrosion resistance, as well as being Ni-free. AISI 430 was evaluated in an artificial sweat solution with the presence of Escherichia coli, and Staphylococcus aureus. Surface microbial analyses did not reveal colonization of bacteria on metallic surfaces, even when bacteria adhesion was investigated in a MüellerHinton solution. However, by electrochemical techniques, the AISI 430 surfaces demonstrated clear signs of corrosion mainly in a sterile medium after two weeks of exposure. 


\section{Introduction}

AISI 430 is ferritic stainless steel, which has been utilized in both the food [1] and medical industry [2] since it is relatively cheaper when compared to austenitic alloys as AISI 304 [3], as well as having an appropriated corrosion resistance and high sensitivity to chlorides [3]. Moreover, it is also essentially Ni-free and does not produce allergies [4], making it a valuable material for use in contact with the skin. Therefore, its features are appropriately used on door handles, handrails, medical devices [2,5,6], and in particular, as a sensor for early diagnosis for type 2 diabetes by electrochemical skin conductance (ESC). This is a simple electrophysiological method used in the functional evaluation of the sweat gland that probes sudomotor/small fiber dysfunction [4]. In this case, small fiber nerves lacking myelinated axons produce a durable shift in the ionic balance and $\mathrm{pH}$ value of sweat conducts $[3,7,8]$. Indeed, it has been reported that the $\mathrm{pH}$ value of the sweat can vary from 4.5 to 7.0 [9-11] due to the damage in the glands [7], sweat-rate [12], and glucose concentration [13].

In previous investigations, stainless steels have been analyzed as new biocompatible sensors $[3,4,14]$. However, the behavior of stainless steels, such AISI 430 surface, has never been adequately determined neither under sweat conditions nor with bacterial adhesion. So far what is known is that Escherichia coli is frequently present in human hands and feet [15], while Staphylococcus aureus is typically transmitted during hospital stays, since they are able to adhere to surfaces due to cell adhesion molecules being closely located around the outer part of the bacterial cell wall; they may even adhere to several types of surfaces, that include medical equipment [16]. The latter is substantially important due to the damage that bacterial colonization can cause, for instance, biocorrosion (MIC) $[17,18]$.

The main goal of this investigation is to analyze the influence of Escherichia coli and Staphylococcus aureus bacteria on the corrosion behavior of AISI 430 surface after exposure to acidic and neutral artificial sweat solutions through the use of surface analysis and electrochemical techniques, specifically the bacterial growth on the surface and its effect on the corrosion rate of the steel. 


\section{2. Experimental}

2.1 Sample and solutions

5 The material studied was a stainless steel AISI 430 (Good Fellow) plate with the following 6 chemical composition (in wt.\%): $0.12 \max . \%$ C, 1 max. \% Mn, $0.004 \max$. P, 0.030 max. \%

7 S, 1 max. \% Si, 16-18\% Cr, 0.50 max. \% Ni, balance Fe. The AISI 430 samples were used 8 as received, which have been polished according to ASTM A480 $\mathrm{N}^{\circ} 8$ to achieve mirror 9 surface, in order to minimize the surface imperfection effects on the electrochemical 10 response. Before exposure, the samples were cleaned using bi-distilled water, and dried under 11 airflow.

13 In this work, the artificial sweat solution (ASS) was prepared under ISO-3160-2 protocol, 14 which contains (in $\mathrm{g} \cdot \mathrm{L}^{-1}$ ): 20 sodium chloride, 17.5 ammonium chloride, 4.76 acetic acid, 15

152 hydroxy-propanoic acid. The solution was made using distilled water, with the $\mathrm{pH}$ being 16 set at 4.7 and 6.5 by using $0.1 \mathrm{M}$ sodium hydroxide solution. Notice that the acid solution 17 corresponds to the case when the peripheral neuropathy is early developed in patients with 18 diabetes [19], producing a durable shift in the ionic balance and $\mathrm{pH}$ value of sweat conducts 19 [3,7-11]. In this condition, glands [7], sweat-rate [12], and glucose concentration [13] can be 20 strongly damaged, therefore, analyzing the metal surfaces that can be in contact with the

21 sweat is very interesting from a corrosion point of view. Additionally, the ASS solution was 22 inoculated with an active inoculum of Escherichia coli BW25113 and Staphylococcus aureus 23 BAA977, separately, which are frequently found on the human skin.

2.2 Microbiological characterization

27 E. coli and S. aureus were grown in a nutritive Müeller-Hinton medium containing $\left(\mathrm{mg} \cdot \mathrm{L}^{-}\right.$

$28{ }^{1}$ ): 2 beef extract, 17.5 casein acid hydrolysate, 1.5 starch, 17.0 agar, along with $1000 \mathrm{~mL}$ of 29 distilled water at $37{ }^{\circ} \mathrm{C}$ overnight. Bacterial growth was controlled by direct Petri dish 30 counting and 96-well plate growth curves under shaking conditions in a Multiskan FC 31 (Thermo) equipment. Bacterial growth was measured at $600 \mathrm{~nm}$. Tests for bacteria adhesion 
were performed by dipping a sample of $1 \mathrm{~cm}^{2}$ of AISI 430 into a stock of E. coli and $S$. aureus $\left(10^{6}\right.$ cells per milliliter) in different solutions, using Müeller-Hinton (MH) broth as a positive control and an artificial sweat solution (ASS) without a nutritional agent, with 0.5 wt.\% glucose (G), 1.0 wt.\% glucose, 0.5 wt.\% lactose (L), 1.0 wt.\% lactose, respectively, at $\mathrm{pH}$ 4.7. Additionally, the artificial sweat solution was set at $\mathrm{pH}: 7.0,6.5,6.0$, and 5.5.

The metallic samples were incubated at $37^{\circ} \mathrm{C}$ during 24 hours in the presence of each type 8 of bacteria, under convective conditions. A $0.01 \mathrm{M}$ sodium cacodylate/ $0.15 \mathrm{M} \mathrm{NaCl}$ buffer 9 with a $7.0 \mathrm{pH}$ was used to rinse the samples twice, with them later being fixed with $1 \%$ glutaraldehyde at $23 \pm 1{ }^{\circ} \mathrm{C}$ for 2 hours. Samples were then dehydrated by using ascending

11 percentages of ethanol $(30 \%, 50 \%, 70 \%, 80 \%, 90 \%$, and $100 \%)$, and later coated with a thin 12 film of $\mathrm{Au}$, all done before being observed by FE-SEM [20].

\subsection{Surface analysis}

The surface of AISI 430 samples was cleaned with bi-distilled water and alcohol before to

17 be characterized by field-emission scanning electron microscopy (FE-SEM) model 18 QUANTA 250 FEG that was equipped with an energy dispersion spectrometer. This was carried out prior to and after 14 days of exposure. Additionally, the chemical compositions of samples were analyzed in depth, before and after exposure to sterile and inoculated artificial sweat solution, by using a Glow-Discharge Optical Emission Spectroscopy (GDOES) model Spectruma Analytik GmbH GDA $750 \mathrm{HR}$, with a $2.5 \mathrm{~mm}$ diameter anode that operates in DC excitation mode. The analysis was carried out in an Ar atmosphere (5.0 quality) with an average discharge pressure of $5 \times 10^{-2} \mathrm{hPa}$, by using the following excitation parameters: $1000 \mathrm{~V}, 12 \mathrm{~mA}$ and $0.1 \mu \mathrm{m} \cdot \mathrm{min}^{-1}$ sputtering rate [21]. All samples were measured in triplicate. In this context, an aliquot of $50 \mu \mathrm{L}$ of each bacteria solution, standardized to $10^{6} \mathrm{CFU} \cdot \mathrm{mL}^{-1}$, was deposited on the AISI 430 surface and incubated for 24 $\mathrm{h}$ at $37^{\circ} \mathrm{C}$. The metal samples were then stained with a live/dead® kit (marking live bacteria

29 in green and dead bacteria in red) and left alone for 15 minutes. Next, samples were washed 30 by applying a $0.85 \mathrm{wt} . \% \mathrm{NaCl}$ solution in order to remove the stain surplus. Moreover, the 
1 samples were placed on the slide, wrapped with a coverslip, and as well as sealed by tape to

2 allow later observation in a Carl Zeiss LSM 700 confocal microscope.

2.4 Electrochemical measurements order to determine the frequency range to analyze [22,23]. Linear sweep voltammetry (LSV)

18 EIS, and LSV were collected after 1, 3, 7, and 14 days of exposure. All samples were 19 electrochemically measured in duplicate.

\section{3. Results and discussion}

3.1 Microbial growth in simulated sweat solution

25 A microbial growth analysis of E. coli and S. aureus on AISI 430 was carried out in both

26 Müeller-Hinton medium (MH) and artificial sweat solution (ASS). Figure 1 shows a dramatic

27 increase in the optical density of S. aureus and E. coli in the Müller-Hinton medium when 28 exposed for short times, followed by a plateau close to 0.35 and 0.4 after a $10 \mathrm{~h}$ exposure, 29 respectively, and a rapid rise after $18 \mathrm{~h}$, reaching a maximum growth near 0.55 after $22 \mathrm{~h}$. 30 However, bacteria did not grow in inoculated ASS, even when glucose and lactose were 31 added as nutritional agents (see Figure S1 in supplementary material). Indeed, the optical 
1 density only increased slightly after $13 \mathrm{~h}$ of exposure in an ASS with a neutral $\mathrm{pH}$ value. It

2 should be mentioned that bacterial adhesion and colonization correspond to the earlier stages

3 in a biofilm formation, and even though those processes do not take place, the metabiological

4 activity may provoke biocorrosion [24,25][26].

5
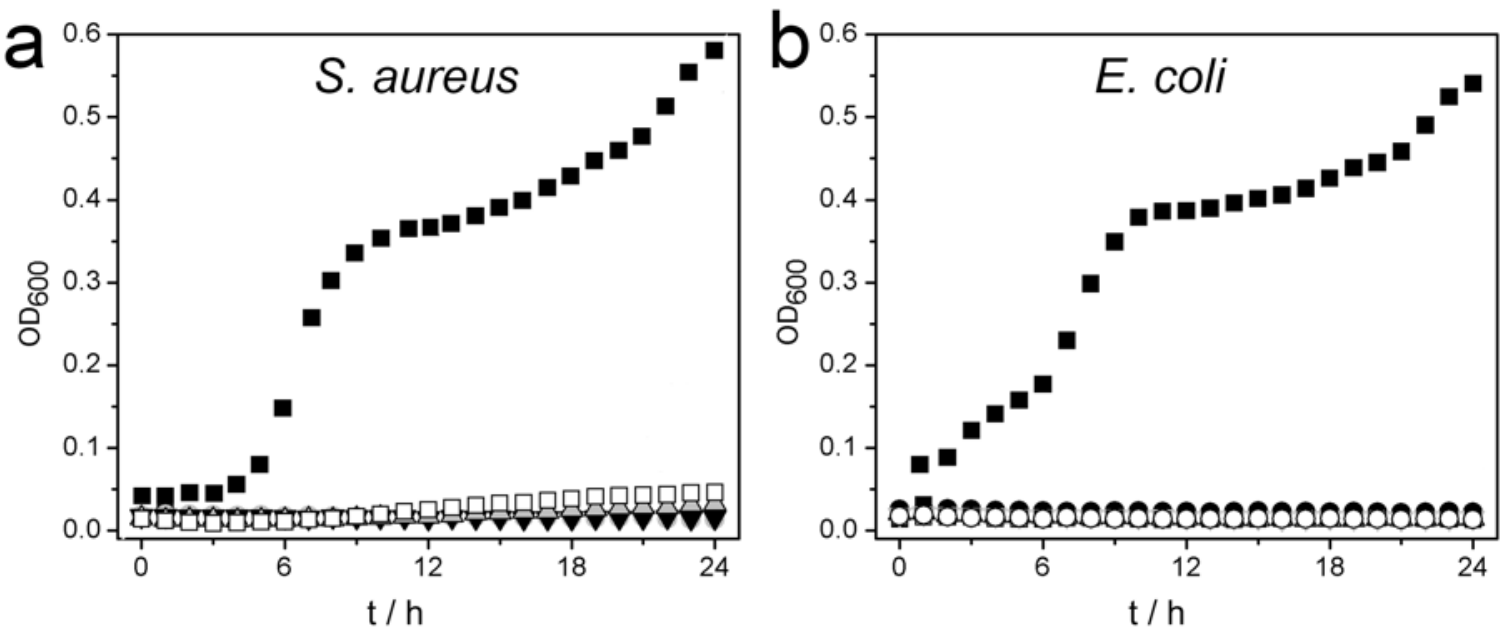

6

12 Figure 2 shows confocal images of the AISI 430 surface after 24 hours of exposure to E. coli

13 and S. aureus in different growth conditions. For both bacterial strains, no adhesion or

14 biofilm formation was observed on the AISI 430 surface FE-SEM images after 24 hours of

15 exposure to various growth solutions for E. coli. Even in the presence of a MH nutrient, both

16 microorganisms were rarely detected, as also seen in Figures S2 and S3. The high chromium

17 content in the AISI 430 steel alloy, and its high toxicity, could explain the extremely low

18 colonization of the microorganism on these types of surfaces [27]. The low presence of

19 bacteria on the metal surface can indicate that the effect of microbially influenced corrosion

20 (MIC) could be ruled out with this type of alloy, which will be later discussed. 

2 FE-SEM images of AISI 430 prior and after 1 day of exposure to ASS sterilized and inoculated at $\mathrm{pH} \mathrm{4.7,} \mathrm{are} \mathrm{presented} \mathrm{in} \mathrm{Figure} \mathrm{3,} \mathrm{revealing} \mathrm{some} \mathrm{polished} \mathrm{defects} \mathrm{(aligned}$

4 lines) and imperfection before exposure (see Figure 3(a)), and some damage related to 5 exposure mainly in inoculated media (see Figure 3(b-d)), which can be associated with the 6 release of the metabolic products, although only some bacteria could be observed due to the 7 cleaning surface treatment carried out after exposure.
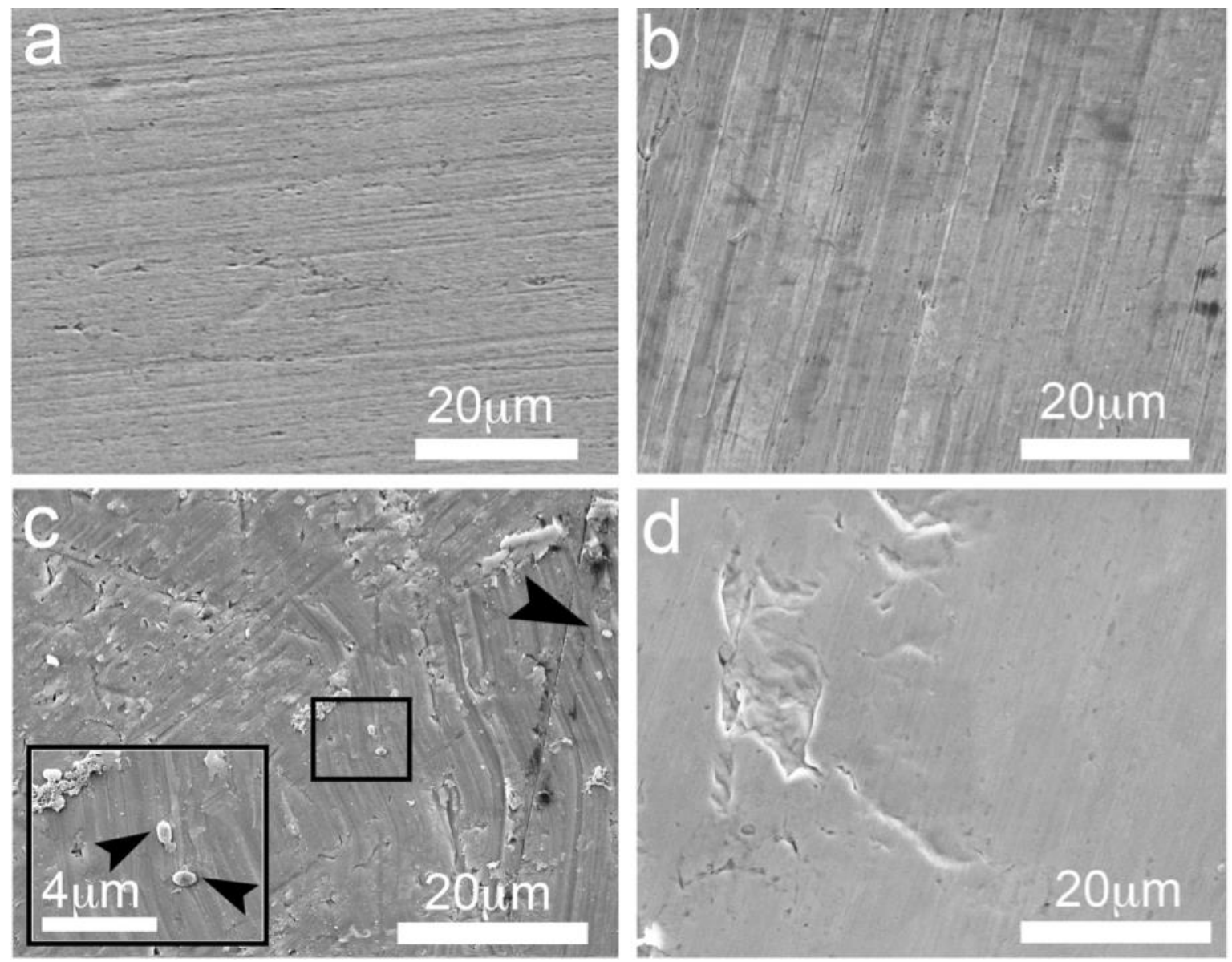

Figure 3. FE-SEM images of AISI 430 (a) prior to and after 14 days of exposure to ASS (b) sterilized and inoculated with (c) S. aureus and (d) E. coli at pH 4.7.

13 It has been reported that the adhesion and colonization of E. coli on metal surfaces produce

14 changes in the interface due to its metabolic products. For instance, Baeza [28] reported how

15 the catalase activity of $E$. coli modifies the oxygen uptake after the colonization on stainless

16 steel. The enzymatic action of catalase promotes an increase in the cathodic current and, 
1 consequently, an increase in the overall corrosion process. It has also been found that the $S$.

2 aureus colonization can produce several metabolic products, where the main one is 3 polysaccharide intercellular adhesin (PIA) [29]. This type of compound acts as an active

4 barrier for the metal [30]. However, after the biofilm establishment, S. aureus produces exo-

5 enzymes and surfactants, such as protease that corresponds to a type of hydrolase [31], and

6 the hydrolase can promote the oxygen concentration at the metal interface, influencing the

7 local $\mathrm{pH}$, and therefore, a modification of the corrosion rate. On the other hand, FE-SEM

8 analysis also revealed that the worst surface damage occurred with the destruction of passive

9 oxide film after 14 days exposed in sterilized medium at $\mathrm{pH} 4.7$, as shown in Figure 4. Similar

10 surface damage has been reported previously by Sekine et al. [32] and Pistorius [33], who

11 studied the same stainless steel but exposed to an acid solution with $\mathrm{pH}=2$ and 2.5, 12 respectively.
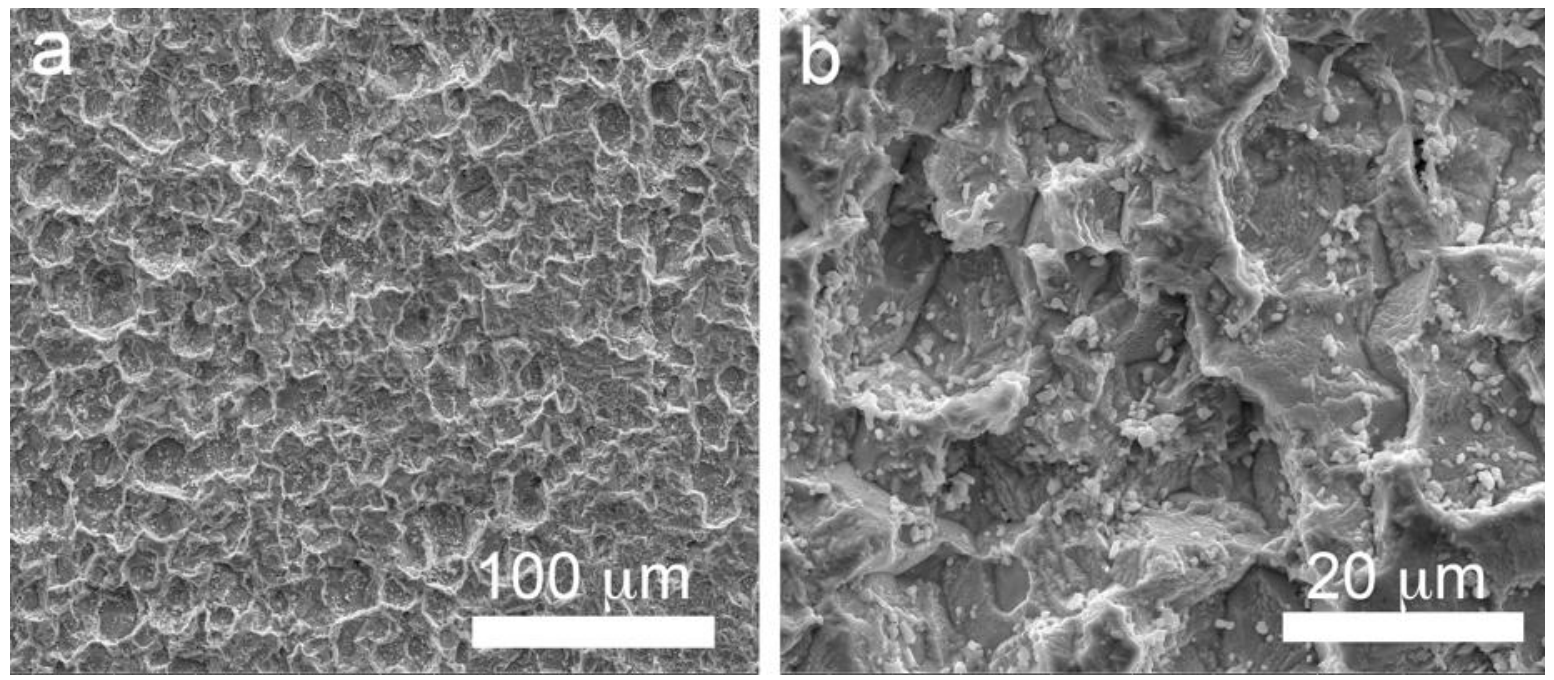

Figure 4. FE-SEM images of AISI 430 after 14 days of exposure to ASS sterilized at pH 4.7. (a)

18 Figure 5 shows the composition profile of AISI 430 determined by GD-OES prior to and 19 after exposure to a sterilized as well as inoculated media at $\mathrm{pH} 4.7$ for 14 days. The 20 composition profile reveals a depletion of the alloying elements until $200 \mathrm{~s}$ of abrasion, which 21 increases until $400 \mathrm{~s}$ in the inoculated media with E. coli and $S$. aureus, and a rise of oxygen 22 content toward the surface. Figure 5(a) insert shows that the oxide layer response was 23 observed until $2.5 \mathrm{~s}$ before exposure, decreasing until $1.5 \mathrm{~s}$ after 14 days of exposure to the 
1 sterilized solution; therefore, the oxide could be present, but with greater roughness and

2 possibly a different chemical composition that can also influence its protective properties.

3 The inserts in figures $\mathrm{c}, \mathrm{d}$ for inoculated media show a rising of alloying elements after $15 \mathrm{~s}$,

4 which were five times greater than in the sterilized solution. This can be associated with an

5 oxide thickness increase, as previously reported [34,35]. Furthermore, the oxide film is

6 composed of a bi-layer, an outer film with a Fe-enrichment at the surface, formed by $\mathrm{FeOOH}$

7 and $\mathrm{Fe}_{3} \mathrm{O}_{4}$, as well as an inner layer with a $\mathrm{Cr}$-enrichment that can be formed by $\mathrm{Cr}_{2} \mathrm{O}_{3}$ and

$8 \mathrm{Cr}(\mathrm{OH})_{3}$, as was previously described by Luo et al. [36] and Wonneberger et al. [37].
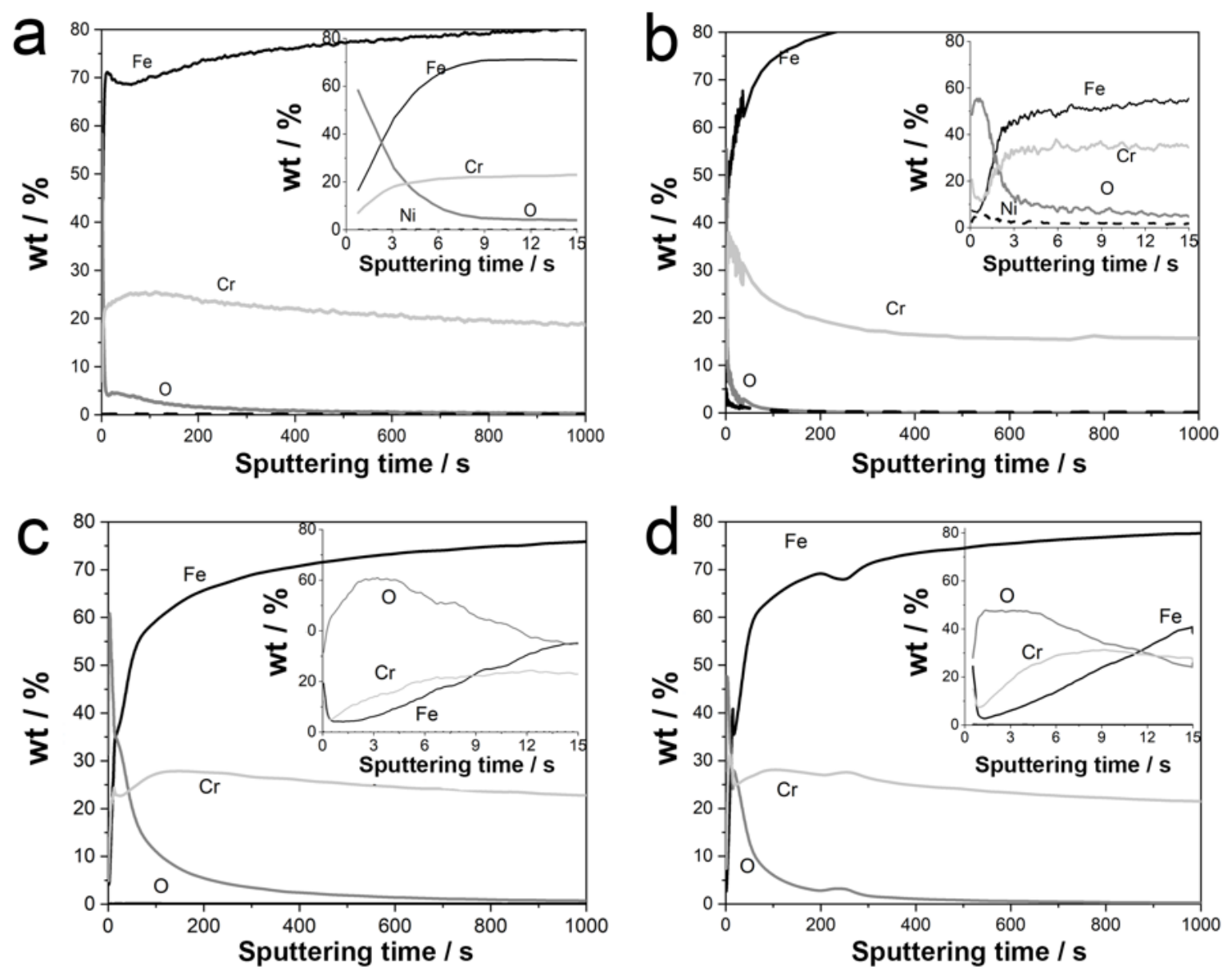

11 Figure 5. Composition profile by GD-OES of AISI 430 (a) prior to and after 14 days of exposure to 
1 It is worth mentioning first that the validity of the impedance diagrams was evaluated using

2 Kramers-Kronig relations that showed residuals of real and imaginary parts of the impedance 3 increased mainly in higher and lower frequency domains [38]. Therefore, the frequency range

4 of the impedance data analyzed generally varied between $10^{4}$ to $10^{-2} \mathrm{~Hz}$, except for 5 inoculated media with $S$. aureus at $\mathrm{pH} 4.7$. Figures $6 \& 7$ show the impedance response for 6 AISI 430 after being exposed to both the sterilized and inoculated ASS with S. aureus and 7 E. coli at $\mathrm{pH} 4.7$ and $\mathrm{pH}$ 6.5, respectively. For all the evaluated solutions, a capacitive 8 behavior was observed, which can be associated with the oxide film formed on the surface, 9 but also with the charge transfer resistance $\left(R_{c t}\right)$ related to the cathodic reaction that can be 10 in parallel with the double layer capacitance, therefore, two-time constant could be 11 superposed in the frequency domain studied, as was previously described by Euch et al. $12[39,40]$. It should be noted that the characteristic frequency $\left(f_{c}\right)$ is shifted during exposure to 13 higher frequencies in sterilized solution and inoculated medium with $S$. aureus. This suggests 14 that the corrosion process took place [41]. However, $f_{c}$ was slightly shifted to lower 15 frequencies in inoculated medium with E. coli. Additionally, Figures 6 and $7(\mathrm{~b}, \mathrm{~d}, \mathrm{f})$ show the 16 Bode plots that were corrected by the electrolyte resistance $\left(R_{e}\right)$, as described by Orazem et 17 al. [42], revealing a plateau possibly due to a constant phase element behavior, however, the 18 phase was slightly influenced mainly at high frequency $\left(10^{2}-10^{4} \mathrm{~Hz}\right)$. This can be associated 19 with the non-uniform primary current distribution in the electrode periphery, as was 20 described by Gharbi et al. [43]. But also, this can be also attributed to the difficulty in 21 estimating the electrolyte resistance $\left(R_{e}\right)$ in some solutions. On the other hand, after being 22 immersed in a sterilized solution with $\mathrm{pH} 4.7$ during 14 days, the sample showed corrosion 23 signs, whose constant-time was solely associated with the charge transfer resistance in 24 parallel to the double layer capacitance.

26 Figures 6 (b) also show in the low-frequency range, the impedance modulus $\left(|Z|_{L F}\right)$ showed 27 a drastic drop in the sterilized medium after exposure, from $10^{5} \Omega \mathrm{cm}^{2}$ to $10^{2} \Omega \mathrm{cm}^{2}$, 28 suggesting the development of the corrosion process with a break on the passive layer and an 29 increase of surface roughness. While in the inoculated medium, the $|Z|_{L F}$ decreased in the 30 presence of $S$. aureus but significantly less than in the sterilized solution, indicating that its 31 metabolic products could act as a barrier to metal release [30]. Conversely, in the presence 
1 of $E$. coli after 14 days, the drop of $|Z|_{L F}$ was stronger than in the presence of the $S$. aureus

2 in both $\mathrm{pHs}$. It could be due to the fact that E. coli develops microorganism induced corrosion

3 as demonstrated by Baeza et al. and Nan et al. [28,44]. Table 1 shows the variation of the

$4 \quad|Z|_{L F}$ for all evaluated systems. At $\mathrm{pH} 4.7$, the phase angle $(-\theta)$ decreased significantly from

$582^{\circ}$ to $45^{\circ}$ in the sterile medium, corroborating that the dissolution of the oxide took place. In

6 the inoculated media, $-\theta$ decreased during exposure, yet the fall being less evident. A similar

7 trend exhibited the impedance response of AISI 430 after exposure at $\mathrm{pH} 6.5$, but less

8 significant, as shown in Figure 7.

9
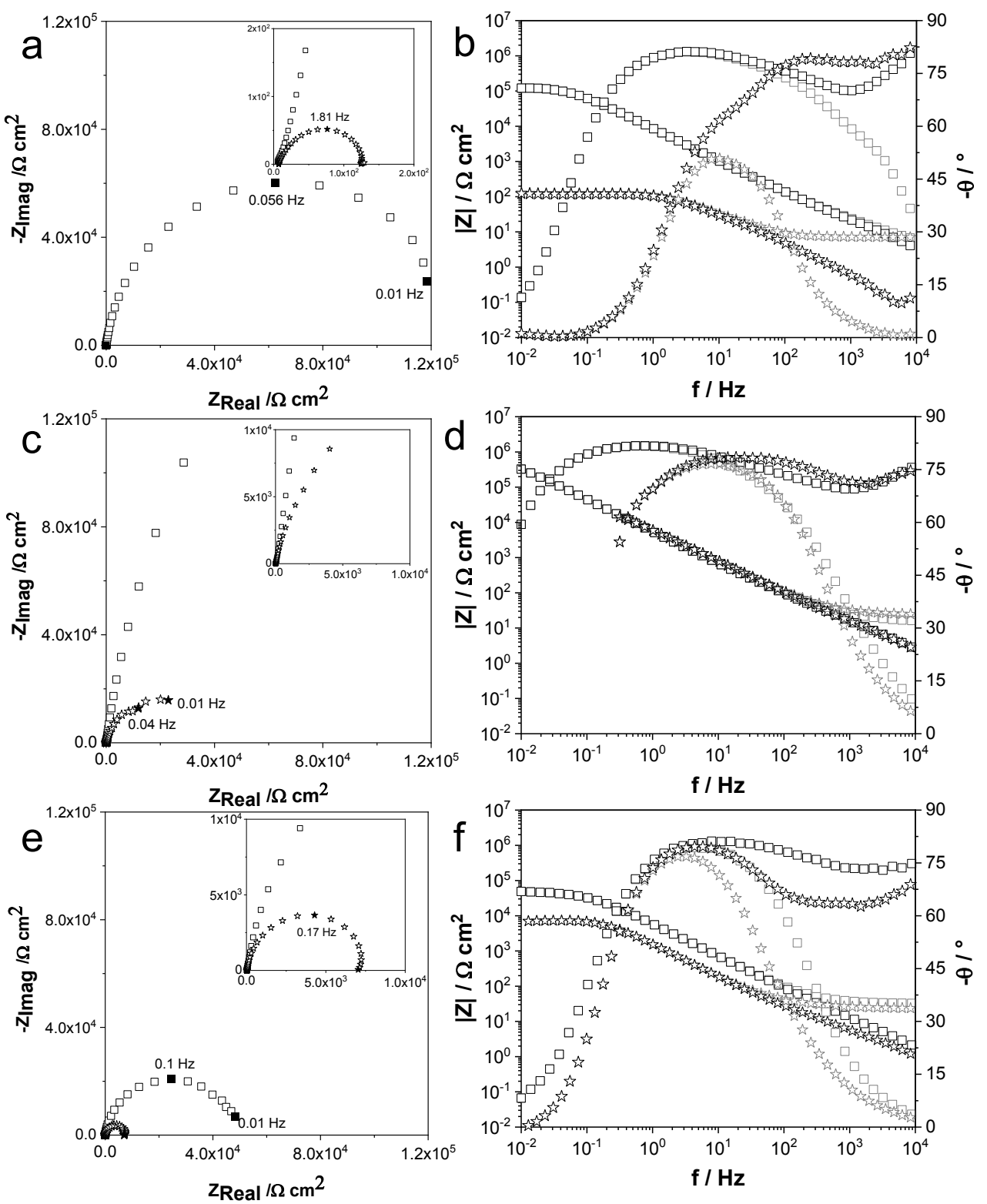
1 Figure 6. Nyquist diagrams and corrected Bode plots of AISI 430 after $(\square) 1$ and ( $₫$ ) 14 days of 2 exposure to ASS (a,b) sterile and inoculated with (c,d) S. aureus and (e,f) E. coli at pH 4.7.
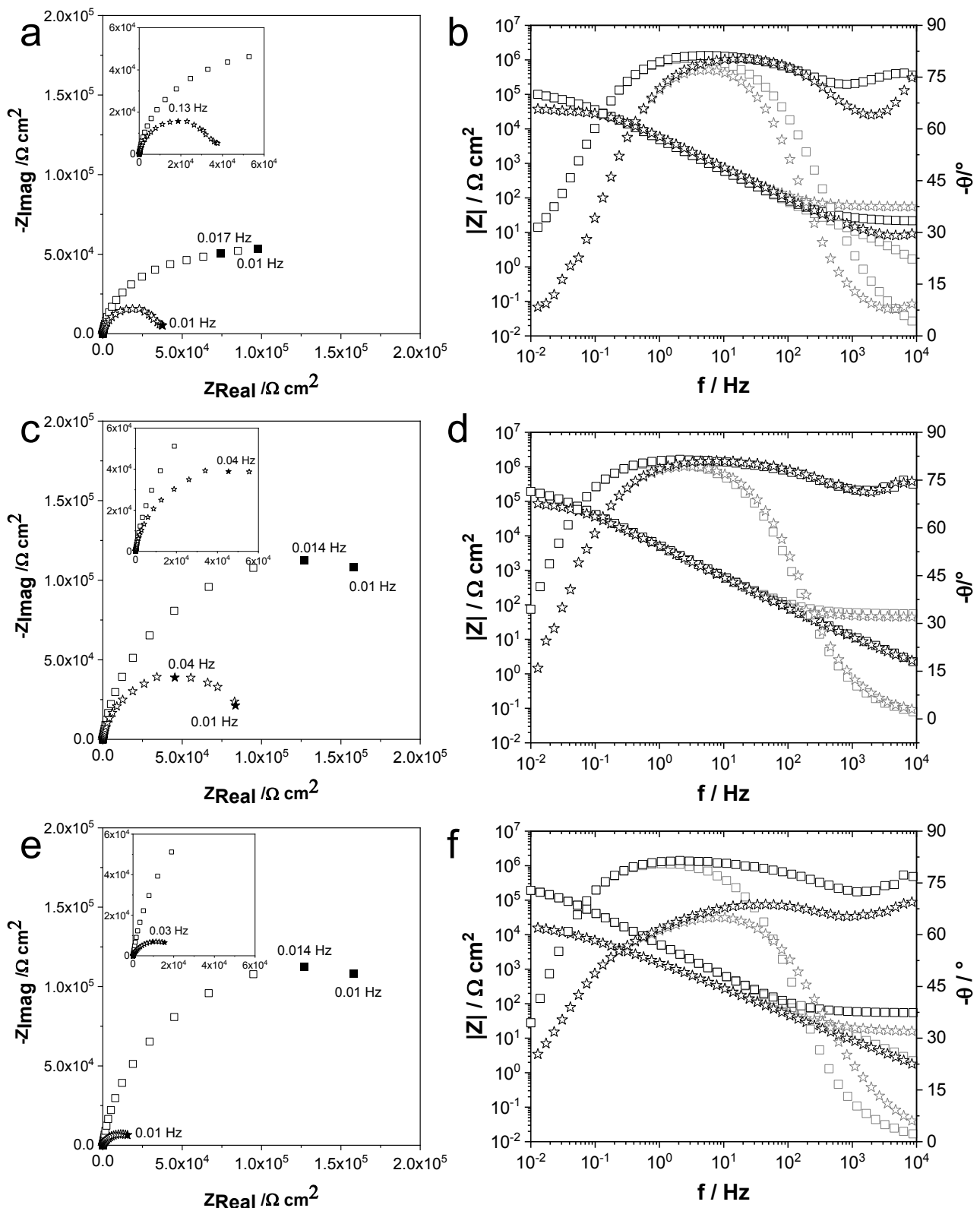

Figure 7. Nyquist diagrams and corrected Bode plots of AISI 430 after ( $\square) 1$ and ( $\star$ ) 14 days of exposure to ASS (a,b) sterile and inoculated with (c,d) S. aureus and (e,f) E. coli at pH 6.5.

7 The variation of the imaginary part $\left(Z_{\text {Imag }}\right)$ versus frequency suggests that the experimental

8 impedance data can be related to a constant phase element (CPE) behavior, as shown in

9 Figure S4 in the supplementary material [38], revealing a linear domain at MF and HF, with

10 a slope $(\alpha)$ lower than -1 [38], as can be seen in Table S1 in the supplementary material. The

11 CPE behavior can be associated with the oxide film formed on the metal surface, but also

12 can be related to the charge transfer resistance due to the cathodic reaction at MF domain. In 
1 order to better understand this behavior. Figure 8 shows the normalized resistivity $\left(\rho / \rho_{0}\right)$ as

2 a function of the position $(\gamma / \rho)$ or $\xi[23,45]$ for all systems evaluated, where the resistivity $\rho$

3 in the oxide/solution and metal/oxide interfaces are represented as $\rho_{\delta}$ and $\rho_{0}$, respectively,

4 while the oxide thickness is $\delta$. It should be noted that $\rho / \rho_{0}$ showed a quick drop after 1 day

5 for all media and after 14 days in $\mathrm{Ph} \mathrm{4.7,} \mathrm{but} \mathrm{revealed} \mathrm{a} \mathrm{more} \mathrm{homogeneous} \mathrm{oxide} \mathrm{layer}$

6 mainly after 14 days in sterilized solution.

7
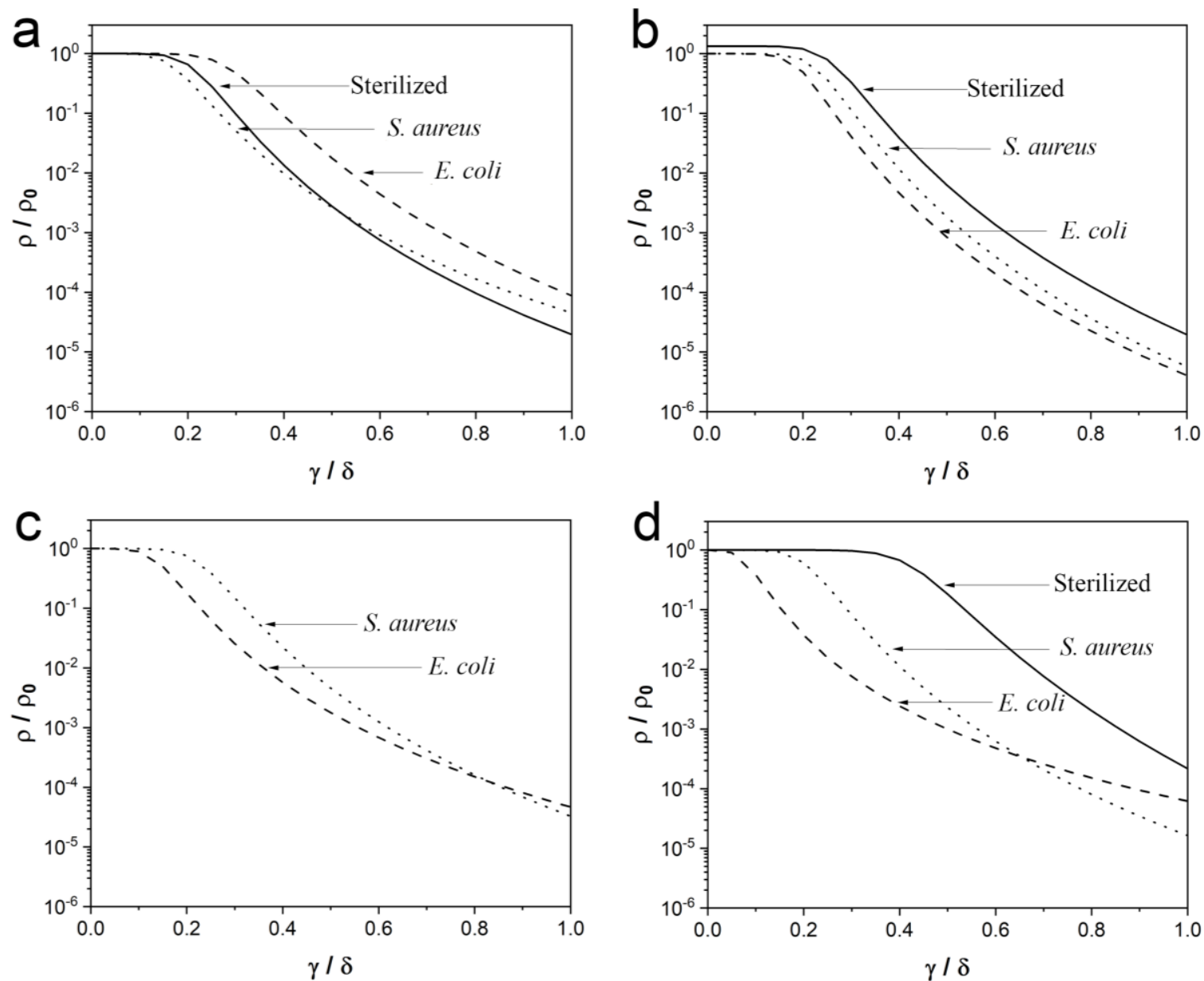

Figure 8. Normalized resistivity as a function of dimensionless position $(\gamma / \delta)$ of AISI 430 after $(a, b)$ and $(--)$ E. coli $(\mathrm{a}, \mathrm{c}) \mathrm{pH} 4.7$ and $(\mathrm{b}, \mathrm{d}) \mathrm{pH} 6.5$.

13 The impedance response related to an oxide film has been described by $[45,46]$ :

14

$$
Z_{\text {oxide }}=\int_{0}^{\delta} \frac{\rho(\gamma)}{1+j \omega \rho(\gamma) \varepsilon(\gamma) \varepsilon_{0}} d \gamma
$$


1 Under the assumption of a uniform permittivity, the impedance of the oxide can be obtained 2 as follow:

$4 \quad Z_{\text {oxide }}=\int_{0}^{\delta} \frac{\rho(\gamma)}{1+j \omega \rho(\gamma) \varepsilon \varepsilon_{0}} d \gamma$

$9 \quad Z(\omega)=g \frac{\delta \rho_{\delta}^{1-\alpha}}{\left(\rho_{0}^{-1}+j \omega \varepsilon \varepsilon_{0}\right)^{\alpha}}$

11 where $\alpha$ corresponds to a CPE parameter, which can also be estimated from the slope of the $12 \log -\log Z_{\text {Imag }}$ vs. frequency plots (see Figure S5), as was previously described. The vacuum

13 permittivity and the dielectric constant of the oxide layer are represented as $\varepsilon_{0}$, which is equal 14 to $8.8542 \times 10^{-14} \mathrm{~F} \cdot \mathrm{cm}^{-1}$, and $\varepsilon$. Additionally, $g$ is a numerical coefficient close to 1 when $\alpha$ 15 is close to 1 , given as:

$g=1+2.88 \gamma^{-2.375}$

where $\gamma$ is estimated from the following relation: $\alpha=(\gamma-1) / \gamma$, and if the $\left(\rho_{0} \varepsilon \varepsilon_{0}\right)^{-1}<$ $\omega<\left(\rho_{\delta} \varepsilon \varepsilon_{0}\right)^{-1}$. It should be mentioned that the $\rho_{0}$ and $\rho_{\delta}$ were determined in the frequency range where the $\mathrm{CPE}$ behavior was observed, taking the lower and upper limits, respectively, which varied between 60-10,000 Hz. Moreover, $Q$ corresponds to a CPE parameter,

The capacitance of the oxide film was estimated as follow:

$C_{\text {oxide }, \text { PLM }}=g Q\left(\rho_{\delta} \varepsilon \varepsilon_{0}\right)^{1-\alpha}$

31 where $C_{\text {oxide,PLM }}$ is the capacitance of the oxide film $[23,45]$. Table 1 summarizes the PLM 32 parameters obtained for all evaluated systems. In the sterile solution, $R_{e}$ was influenced by 33 the $\mathrm{pH}$, the lowest being at $\mathrm{pH} 4.7$ rather than at $\mathrm{pH} 6.5$, suggesting a higher metal ion 34 concentration at the electrolyte/oxide interface, with the more acidic $\mathrm{pH}$ possibly being due 
1 to a corrosion process. The $R_{e}$ was modified in the presence of E. coli and S. aureus media, 2 being close to $30 \Omega \cdot \mathrm{cm}^{2}$. As was reported above, Figure S4 revealed two slopes identified

3 with different values for $\alpha$. Therefore, two $Q$ coefficients were determined, which can be 4 associated with the double layer capacitance with the oxide layer. In both cases, the $Q$ 5 coefficients increased slightly at $\mathrm{pH} 4.7$, and any trend was observed at $\mathrm{pH}$ 6.5. It should be 6 noted that the $Q$ coefficient at HF range rised in inoculated medium with $E$. coli between 7 7 and 14 days of exposure, which can be associated with a modification of the passive film 8 properties [47], that was named as $Q_{P L M}$ in this work. Wan et al. [48] investigated SS 316L

9 exposed to E. coli, showing that it had negatively influenced the corrosion process, which 10 was observed after 7 days of exposure. This was attributed to the metabolic products 11 generated and exo-polymeric substances (EPC), which could modify the metal/electrolyte 12 chemical interface. On the other hand, $\alpha$ did not show a clear trend in the acidic and neutral $13 \mathrm{pHs}$, at MF and HF domains, nor with the presence of bacteria. Nonetheless, it should be 14 mentioned that $\alpha$ value was larger at MF than at HF range, which can reveal the frequency 15 distribution over the oxide surface possibly due to its roughness and heterogeneity. From 16 PLM [38] the thickness of the oxide was estimated, revealing a decrease in the sterile solution 17 and in the inoculated media, which was more significant in sterilized solution at $\mathrm{pH} 4.7$, as 18 shown in Table 1 . Those values are in accordance with the drop of the $|\mathrm{Z}|_{\mathrm{LF}}$.

20 Complex capacitance was estimated, as was previously described by Benoit et al. [49-51] 21 and Barrès et al. [49-51], who used the following equations:

$23 \quad C_{\text {Imag }}=\frac{-Z_{\text {Real }}}{2 \pi f x(|Z|)^{2}}$

30 conditions at $\mathrm{pH} 4.7$ and 6.5, which were obtained by using the extrapolation of Cole-Cole 31 plots at HF range, as was previously described [52] (not shown here). In the sterile solution, 32 the $\mathrm{C}_{\text {complex }}$ was strongly modified overtime at $\mathrm{pH} 4.7$ and $\mathrm{pH} 6.5$. In inoculated media, the 
1 complex capacitances were not influenced by $S$. aureus, but the complex capacitances were

2 affected by E. coli, in particular, after 7 days of exposure. From the $\mathrm{C}_{\text {complex }}$, the oxide

3 thickness was also estimated, as was previously described by Tran [46], Benoit [47], and

4 Barrès [48]:

5

6

Table 1. Impedance parameters for AISI 430 exposed to ASS estimated graphically. The oxide thickness was estimated by using a PLM with an average of $\rho_{\delta}=3.7 \times 10^{-6} \Omega \mathrm{cm}$

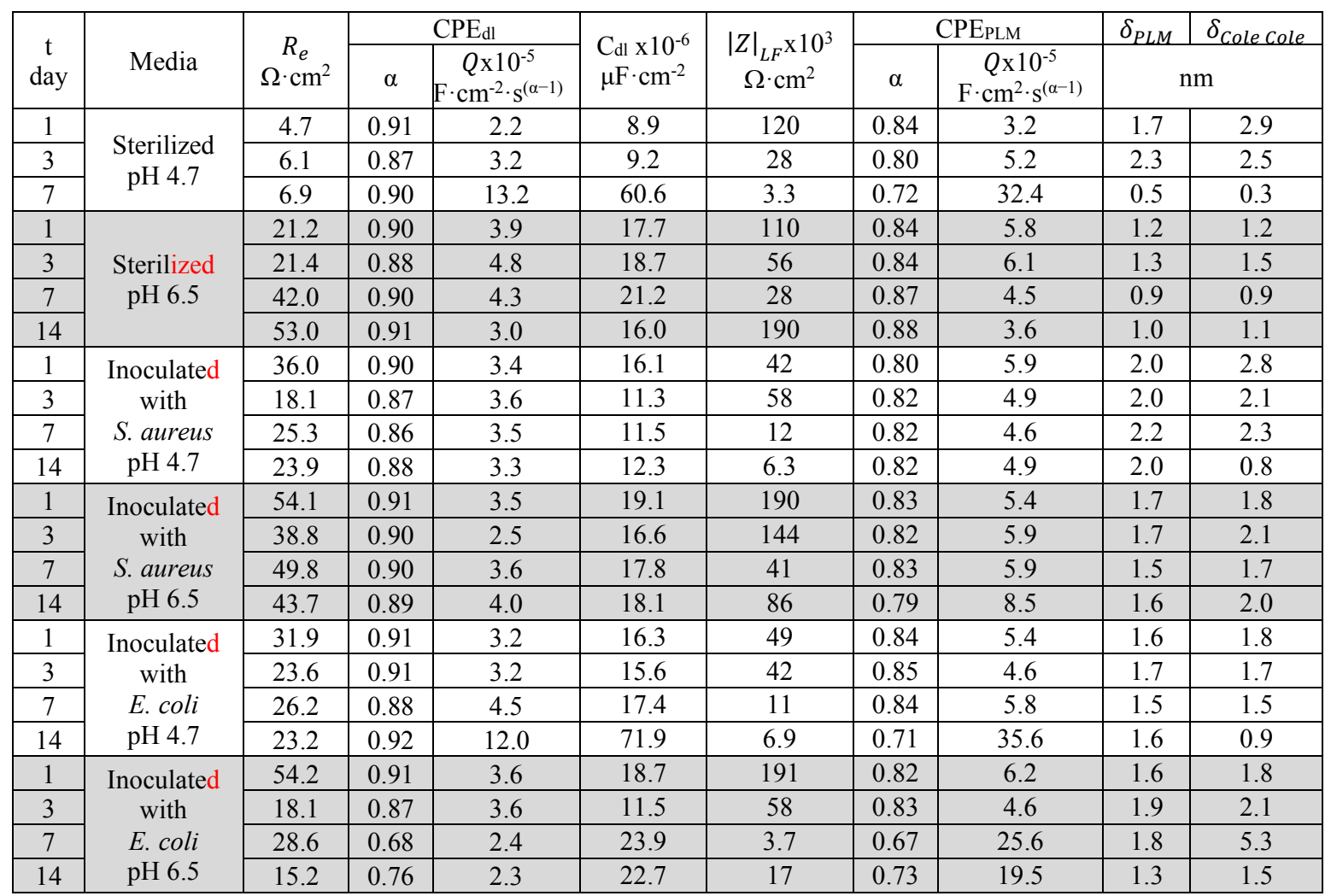

12 In this case, $\varepsilon_{0}$ and $\varepsilon$ are also the vacuum permittivity and the dielectric constant for the oxide 13 film [4,49-51], with a $\varepsilon=15.6$ value [53] since, as previously reported for AISI 304, the 14 value should be close for AISI 430 [49-51]. Figures 9 (b,d) shows that the oxide thickness 15 decreased overtime in the sterilized at $\mathrm{pH} 4.7$, while in the neutral $\mathrm{pH}$, it increased slightly 16 from 3 to $8 \mathrm{~nm}$. Notice that the error bars were obtained from measurements made in 17 duplicate samples to show the reproducibility. The thickness was not influenced in inoculated 18 media at $\mathrm{pH} 4.7$, but surprisingly, it was affected in neutral $\mathrm{pH}$. Therefore, it seems that the 
1 bacteria did not accelerate the corrosion process, even in an acidic medium. It should be

2 mentioned that the values obtained through $\mathrm{C}_{\text {complex }}$ were slightly higher than the values

3 obtained by PLM (see Table 1), being similar to that reported previously for stainless steel

$4[34,35]$. This can be associated with the capacitive contribution of the complex ohmic

5 impedance, but also due to the $R_{e}$ estimation, since a low error in its value can strongly

6 influence the infinitive complex capacitances and the oxide thickness. For instance, an error

7 around $5 \%$ in the $R_{e}$ can mean an error around 20\% of the capacitances estimation, as was

8 previously described by Liao et al. [23].

9
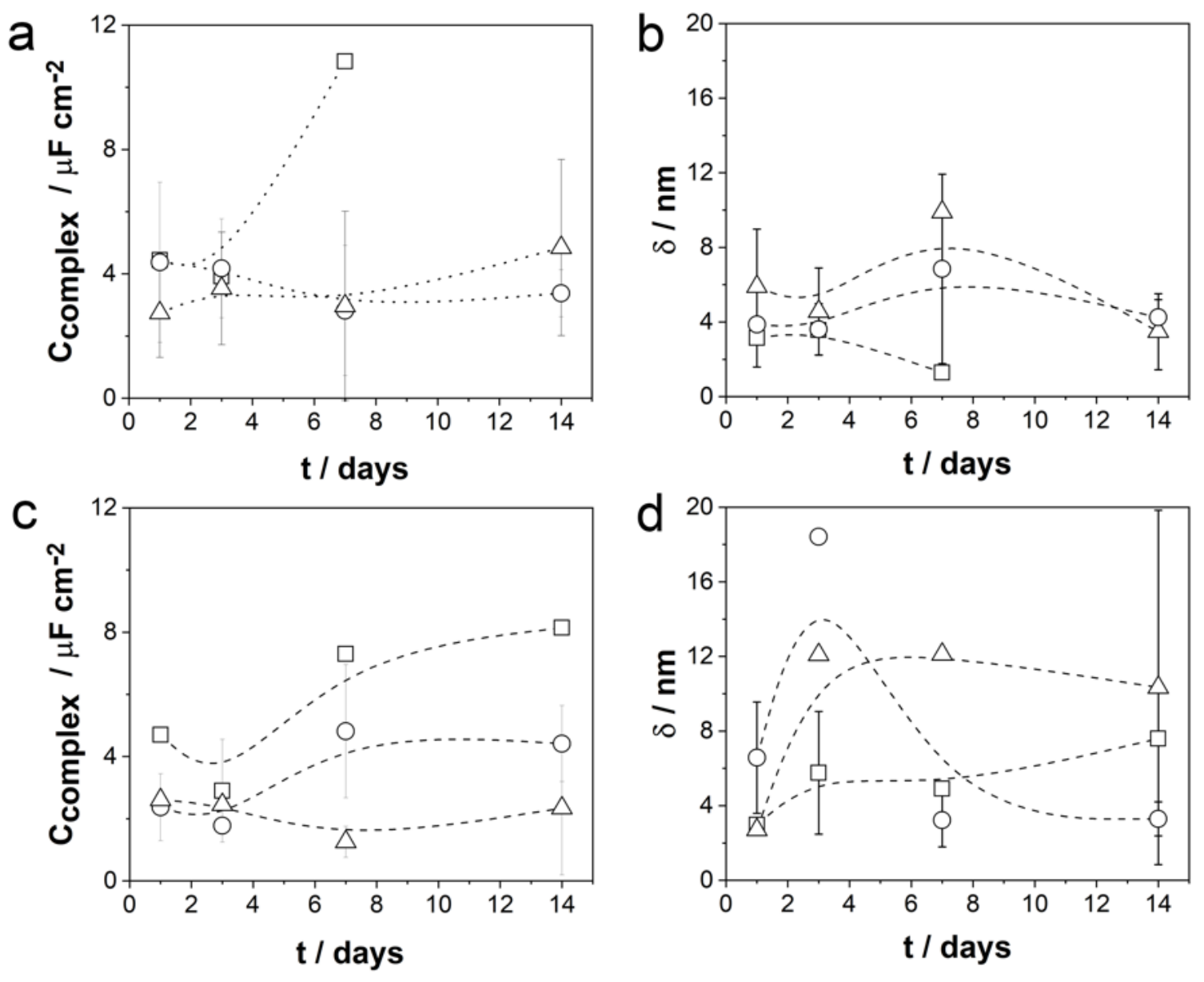

11 Figure 9. (a,c) Infinitive complex capacitance estimated from high-frequency limit of the real part 12 Cole-Cole plots and (b,d) oxide thickness of AISI 430 after exposure to ASS in ( $\square$ ) sterilized and 13 inoculated media with $(\mathrm{O})$ S. aureus and $(\triangle)$ E. coli as a function of time. (a,b) $\mathrm{pH} 4.7$ and (c,d) pH 6.5. 
1 Furthermore, the corrosion potential $\left(E_{\text {corr }}\right)$, anodic current $\left(i_{a}\right)$, and polarization resistance

$2\left(R_{p}\right)$ of AISI 430 were estimated from the LSV (see Figure S6 in the supplementary material)

3 according to ASTM G102. Table 2 shows that in the sterilized acidic medium, $E_{\text {corr }}$ was

4 shifted towards more negative values, $i_{a}$ increased, and $R_{p}$ decreased drastically. This is in

5 agreement with what was reported by Hamidah et al. [54], who studied the corrosion

6 behavior of AISI 304 stainless steel at different $\mathrm{NaCl}$ concentrations by using gravimetric

7 measurements. However, those parameters were not significantly influenced in the neutral

8 sterilized solution. Therefore, if the AISI 430 is exposed to a corrosive solution, as can be

9 considered in the ASS at $\mathrm{pH} 4.7$, it is expected that a corrosion process of this material could

10 take place after 7 days of continuous exposure. In the inoculated media with a neutral

$11 \mathrm{pH}, E_{c o r r}$ and $i_{a}$ did not show a clear trend, while $R_{p}$ increased in the presence $S$. aureus, but

12 decreased significantly in the presence of E. coli. In the inoculated media with acidic $\mathrm{pH}$, the

13 electrochemical parameters did not show a trend with exposure.

14

15

16

17

18

19

20

Table 2. LSV parameters of AISI 430 after exposure to ASS at pH 4.7 and 6.5

\begin{tabular}{|c|c|c|c|c|c|c|}
\hline \multirow[b]{2}{*}{$\begin{array}{c}\mathrm{t} \\
\text { (day) }\end{array}$} & \multicolumn{3}{|c|}{ Sterilized at $\mathrm{pH} 4.7$} & \multicolumn{3}{|c|}{ Sterilized at pH 6.5} \\
\hline & $\begin{array}{c}E_{\text {corr }} \\
\text { (mV vs. } \\
\text { SCE) }\end{array}$ & $\begin{array}{c}i_{a} \times 10^{-4} \text { at } \mathrm{E}=\mathrm{E}_{\mathrm{ocp}}+10 \mathrm{mV} \\
\left(\mathrm{mA} \cdot \mathrm{cm}^{-2}\right)\end{array}$ & $\begin{array}{c}R_{p} \\
\left(\Omega \cdot \mathrm{cm}^{2}\right)\end{array}$ & $\begin{array}{l}E_{\text {corr }} \\
\text { (mV vs. } \\
\text { SCE) }\end{array}$ & $\begin{array}{c}i_{a} \times 10^{-4} \text { at } \mathrm{E}=\mathrm{E}_{\mathrm{ocp}}+10 \mathrm{mV} \\
\left(\mathrm{mA} \cdot \mathrm{cm}^{-2}\right)\end{array}$ & $\begin{array}{c}R_{p} \\
\left(\Omega \cdot \mathrm{cm}^{2}\right)\end{array}$ \\
\hline 1 & -403.8 & 0.1 & 9090.9 & -465.4 & 1.3 & 8842.1 \\
\hline 3 & -535.3 & 0.5 & 2105.2 & -527.7 & 0.6 & 13927.6 \\
\hline 7 & -642.3 & 4.6 & 246.9 & -406.9 & 6.6 & 1287.0 \\
\hline \multirow[t]{2}{*}{14} & -654.8 & 120.9 & 11.1 & -455.3 & 5.3 & 1234.5 \\
\hline & \multicolumn{3}{|c|}{ S. aureus at $\mathrm{pH} 4.7$} & \multicolumn{3}{|c|}{ S. aureus at $\mathrm{pH} 6.5$} \\
\hline 1 & -285.8 & 3.6 & 1023.2 & -356.0 & 0.4 & 2083.3 \\
\hline 3 & -316.2 & 5.0 & 64102.5 & -530.0 & 0.6 & 13210.0 \\
\hline 7 & -317.8 & 2.3 & 2127.7 & -355.3 & 0.7 & 11363.6 \\
\hline \multirow[t]{2}{*}{14} & -137.6 & 3.6 & 270.3 & -334.9 & 0.8 & 10183.3 \\
\hline & \multicolumn{3}{|c|}{ E. coli at $\mathrm{pH} 4.7$} & \multicolumn{3}{|c|}{ E. coli at $\mathrm{pH} 6.5$} \\
\hline 1 & -324.4 & 1.1 & 12820.5 & -104.7 & 0.2 & 33222.6 \\
\hline 3 & -641.1 & 2.6 & 2923 & -22.7 & 0.04 & 27777.8 \\
\hline 7 & -655.3 & 7.4 & 970.8 & -442.2 & 6.7 & 1574.8 \\
\hline 14 & -316.3 & 1.5 & 5714.3 & -273.3 & 4.8 & 1789.5 \\
\hline
\end{tabular}

\section{Conclusion}


1 The behavior of AISI 430 after being exposed to mimic electrolytic sweat solutions used in

2 Sudoscan $^{\mathrm{TM}}$ technology, was analyzed by electrochemical measurements and surface

3 analysis. AISI 430 can be considered as a suitable material that can be employed in massive

4 spaces.

6 Kinetics analyses reveal that Escherichia coli and Staphylococcus aureus did not grow in the

7 inoculated artificial sweat solution, as was observed in Müeller-Hinton medium, even with a

8 differentiating $\mathrm{pH}$ between 4.7 and 6.5. Additionally, scanning electron microscopy analysis

9 did not show colonization of such bacteria over the metallic surface. Electrochemical

10 measurements show that the corrosion effect caused by S. aureus can be discarded, however,

11 E. coli should be considered.

13 Therefore, AISI 430 has excellent performance as a sensor, even in an aggressive medium,

14 i.e. for people with acidic sweat. Nevertheless, the electrochemical impedance response for 15 this material reveals a short lifespan. Indeed, the corrosion rate increases dramatically as a 16 function of exposure time, particularly after 7 days.

18 Acknowledgments

19 The authors would like to thank: France-Chile ECOS (Grants C14E03 and C17E07), 20 Fondecyt (Grant 1160604), Conicyt PFCHA/Doctorado Becas Chile/2019 (Grant 21 21190220), Fondequip (EQM 160091 and 150101), VRIDEI Usach (021942PC-PAP \& 22 051742PC_DAS), and DICYT PS:539 for financial support.

\section{5. References}

24 [1] E. Partington, Stainless Steel in the Food and Beverage Industry, Mater. Appl. Ser. 7 25 (2006) 28.

26 [2] T. Newson, Stainless Steels - Applications, Grades and Human Exposure, (2001) 127 31.

28 [3] A. Calmet, A. Amar, S. Griveau, V. Lair, E. Sutter, F.J. Recio, P. Brunswick, F. 
Bedioui, M. Cassir, Corrosion Behavior of Biocompatible Stainless Steels in Physiological Medium for Non-invasive Diagnosis of Small Fiber Neuropathies Applications, Electroanalysis. 28 (2016) 380-384. https://doi.org/10.1002/elan.201500307.

[4] A. Calmet, N. Vejar, X. Gonzalez, M. Sancy, A. Ringuedé, V. Lair, S. Griveau, J.H. Zagal, F. Bedioui, M. Cassir, Electrochemical Behavior of Stainless Steels for Sudomotor Dysfunction Applications, Electroanalysis. 30 (2018) 162-169. https://doi.org/10.1002/elan.201700464.

[5] Ulrich Heubner, Stainless Steel - When Health Comes First, Belgium, 2009.

[6] J. Davis, Handbook of Materials for Medical Devices, ASM Int. (2003) 205-216. https://doi.org/10.1361/hmmd2003p001.

[7] M. Voortman, D. Fritz, O.J.M. Vogels, F. Eftimov, D. Van De Beek, M.C. Brouwer, M. Drent, Small fiber neuropathy: A disabling and underrecognized syndrome, Curr. Opin. Pulm. Med. 23 (2017) 447-457. https://doi.org/10.1097/MCP.0000000000000413.

[8] A. Calmet, K. Khalfallah, H. Ayoub, V. Lair, S. Griveau, P. Brunswick, F. Bedioui, M. Cassir, Small fiber neuropathy diagnosis by a non-invasive electrochemical method: Mimicking the in-vivo responses by optimization of electrolytic cell parameters, Electrochim. Acta. 140 (2014) 37-41. https://doi.org/10.1016/j.electacta.2014.02.053.

[9] F. HERRMANN, L. MANDOL, Studies of $\mathrm{pH}$ of sweat produced by different forms of stimulation., J. Invest. Dermatol. 24 (1955) 225-246. https://doi.org/10.1038/jid.1955.36.

[10] Y.W. Song, D.Y. Shan, E.H. Han, Corrosion behaviors of electroless plating Ni-P coatings deposited on magnesium alloys in artificial sweat solution, Electrochim. Acta. 53 (2007) 2009-2015. https://doi.org/10.1016/j.electacta.2007.08.062.

[11] C. Prakash, P. Bhargave, S. Tiwari, B. Majumdar, R.K. Bhargava, Skin surface pH in acne, J. Clin. Aesthet. Dermatol. 10 (2017) 33-39.

[12] S. Coyle, D. Morris, K.T. Lau, D. Diamond, N. Taccini, D. Costanzo, P. Salvo, F. Di Francesco, M.G. Trivella, J.A. Porchet, J. Luprano, Textile sensors to measure sweat pH and sweat-rate during exercise, 2009 3rd Int. Conf. Pervasive Comput. Technol. 
Healthc. - Pervasive Heal. 2009, PCTHealth 2009. (2009). https://doi.org/10.4108/ICST.PERVASIVEHEALTH2009.5957.

[13] D. Bruen, C. Delaney, L. Florea, D. Diamond, Glucose sensing for diabetes monitoring: Recent developments, Sensors. 17 (2017) 1-21. https://doi.org/10.3390/s17081866.

[14] H. Ayoub, S. Griveau, V. Lair, P. Brunswick, M. Cassir, F. Bedioui, Electrochemical Characterization of Nickel Electrodes in Phosphate and Carbonate Electrolytes in View of Assessing a Medical Diagnostic Device for the Detection of Early Diabetes, Electroanalysis. 22 (2010) 2483-2490. https://doi.org/10.1002/elan.201000307.

[15] S. Noor, R.U. Khan, J. Ahmad, Understanding Diabetic Foot Infection and its Management, Diabetes Metab. Syndr. Clin. Res. Rev. 11 (2017) 149-156. https://doi.org/10.1016/j.dsx.2016.06.023.

[16] M.R. Kiedrowski, A.R. Horswill, New approaches for treating staphylococcal biofilm infections, Ann. N. Y. Acad. Sci. 1241 (2011) 104-121. https://doi.org/10.1111/j.1749-6632.2011.06281.x.

[17] E. Medilanski, K. Kaufmann, L.Y. Wick, O. Wanner, H. Harms, Influence of the surface topography of stainless steel on bacterial adhesion, Biofouling. 18 (2002) 193-203. https://doi.org/10.1080/08927010290011370.

[18] M.A. Javed, P.R. Stoddart, S.L. McArthur, S.A. Wade, The effect of metal microstructure on the initial attachment of Escherichia coli to 1010 carbon steel, Biofouling. 29 (2013) 939-952. https://doi.org/10.1080/08927014.2013.820826.

[19] F. Bedioui, V. Lair, S. Griveau, A. Ringuedé, J.H. Zagal, M. Cassir, Electrochemical Behavior of Electrode Materials (Nickel and Stainless Steels) for Sudomotor Dysfunction Applications: A Review, Electroanalysis. 30 (2018) 2525-2534. https://doi.org/10.1002/elan.201800439.

[20] L. Tamayo, D. Acuña, A.L. Riveros, M.J. Kogan, M.I. Azócar, M. Páez, M. Leal, M. Urzúa, E. Cerda, Porous Nanogold/Polyurethane Scaffolds with Improved Antibiofilm, Mechanical, and Thermal Properties and with Reduced Effects on Cell Viability: A Suitable Material for Soft Tissue Applications, ACS Appl. Mater. Interfaces. 10 (2018) 13361-13372. https://doi.org/10.1021/acsami.8b02347.

[21] GDA 550 HR / GDA 750 HR - Spectruma Website (english), (n.d.). 
https://www.spectruma.de/en/gda-550-hr-gda-750-hr.html (accessed 10 October 2019).

[22] C. You, M.A. Zabara, M.E. Orazem, B. Ulgut, Application of the Kramers-Kronig Relations to Multi-Sine Electrochemical Impedance Measurements, J. Electrochem. Soc. 167 (2020) 020515. https://doi.org/10.1149/1945-7111/ab6824.

[23] H. Liao, W. Watson, A. Dizon, V. Vivier, B. Tribollet, M.E. Orazem, Physical Properties Obtained from Measurement Model Analysis of Impedance Measurements, Electrochim. Acta. 354 (2020) 1-26. https://doi.org/10.1016/j.electacta.2020.136747.

[24] I.B. Beech, M. Sztyler, C.C. Gaylarde, W.L. Smith, J. Sunner, Biofilms and biocorrosion, in: Underst. Biocorrosion, Elsevier, 2014: pp. 33-56. https://doi.org/10.1533/9781782421252.1.33.

[25] H.A. Videla, Manual of Biocorrosion, Routledge, 2018. https://doi.org/10.1201/9780203748190.

[26] T.E. Shehata, A.G. Marr, Effect of nutrient concentration on the growth of Escherichia coli., J. Bacteriol. 107 (1971) 210-216.

[27] A.J. Paine, Mechanisms of chromium toxicity, carcinogenicity and allergenicity: Review of the literature from 1985 to 2000, Hum. Exp. Toxicol. 20 (2001) 439-451. https://doi.org/10.1191/096032701682693062.

[28] S. Baeza, N. Vejar, M. Gulppi, M. Azocar, F. Melo, A. Monsalve, J. Pérez-Donoso, C.C. Vásquez, J. Pavez, J.H. Zagal, X. Zhou, G.E. Thompson, M.A. Páez, New evidence on the role of catalase in Escherichia coli-mediated biocorrosion, Corros. Sci. 67 (2013) 32-41. https://doi.org/10.1016/j.corsci.2012.09.047.

[29] J.L. Lister, A.R. Horswill, Staphylococcus aureus biofilms: Recent developments in biofilm dispersal, Front. Cell. Infect. Microbiol. 4 (2014) 1-9. https://doi.org/10.3389/fcimb.2014.00178.

[30] I.B. Beech, J. Sunner, Biocorrosion: Towards understanding interactions between biofilms and metals, Curr. Opin. Biotechnol. 15 (2004) 181-186. https://doi.org/10.1016/j.copbio.2004.05.001.

[31] D. Vázquez-Sánchez, P. Rodríguez-López, Biofilm Formation of Staphylococcus aureus, Elsevier Inc., 2018. https://doi.org/10.1016/b978-0-12-809671-0.00005-x. 
1 [32] I. SEKINE, H. UsuI, S. KITAGAWA, M. YUASA, L. SILAO, The effect of fluoride ions on the corrosion of steel materials in $\mathrm{H}_{2} \mathrm{SO}_{4}$ and $\mathrm{CH}_{3} \mathrm{COOH}$ solutions, Corros. Sci. 36 (1994) 1411-1424.

[33] P.C. Pistorius, Accelerated corrosion of stainless steel in thiocyanate - containing solutions, 2012.

[34] K. Shimizu, H. Habazaki, P. Skeldon, G.E. Thompson, Impact of RF-GD-OES in practical surface analysis, Spectrochim. Acta - Part B At. Spectrosc. 58 (2003) 15731583. https://doi.org/10.1016/S0584-8547(03)00133-2.

[35] C.O.A. Olsson, D. Landolt, Passive films on stainless steels - Chemistry, structure and growth, Electrochim. Acta. 48 (2003) 1093-1104. https://doi.org/10.1016/S0013-4686(02)00841-1.

[36] H. Luo, H. Su, C. Dong, K. Xiao, X. Li, Electrochemical and passivation behavior investigation of ferritic stainless steel in alkaline environment, Constr. Build. Mater. 96 (2015) 502-507. https://doi.org/10.1016/j.conbuildmat.2015.08.052.

[37] R. Wonneberger, M. Seyring, K. Freiberg, A. Carlsson, J. Rensberg, B. Abendroth, H. Stöcker, M. Rettenmayr, A. Undisz, Oxidation of stainless steel 316L - Oxide grains with pronounced inhomogeneous composition, Corros. Sci. 149 (2019) 178184. https://doi.org/10.1016/j.corsci.2018.12.035.

[38] M.E. Orazem, B. Tribollet, Constant-Phase Elements in: Electrochemical Impedance Spectroscopy, (2017) 395-419. https://doi.org/10.1002/9781119363682.

[39] S. EL Euch, D. Bricault, H. Cachet, E.M.M. Sutter, M.T.T. Tran, V. Vivier, N. Engler, A. Marion, M. Skocic, B. Huerta-Ortega, Temperature dependence of the electrochemical behavior of the $690 \mathrm{Ni}$-base alloy between 25 and $325^{\circ} \mathrm{C}$, Electrochim. Acta. 317 (2019) 509-520. https://doi.org/10.1016/j.electacta.2019.05.131.

[40] Z. Zhang, B. Ter-Ovanessian, S. Marcelin, B. Normand, Investigation of the passive behavior of a Ni-Cr binary alloy using successive electrochemical impedance measurements, Electrochim. Acta. 353 (2020) 136531. https://doi.org/10.1016/j.electacta.2020.136531.

[41] M. Meeusen, L. Zardet, A.M. Homborg, M. Lekka, F. Andreatta, L. Fedrizzi, B. Boelen, J.M.C. Mol, H. Terryn, The effect of time evolution and timing of the 
electrochemical data recording of corrosion inhibitor protection of hot-dip galvanized steel, Corros. Sci. 173 (2020) 108780.

[42] M.E. Orazem, N. Pébère, B. Tribollet, Enhanced Graphical Representation of Electrochemical Impedance Data, J. Electrochem. Soc. 153 (2006) B129. https://doi.org/10.1149/1.2168377.

[43] O. Gharbi, A. Dizon, M.E. Orazem, M.T.T. Tran, B. Tribollet, V. Vivier, From frequency dispersion to ohmic impedance: A new insight on the high-frequency impedance analysis of electrochemical systems, Electrochim. Acta. 320 (2019) 134609. https://doi.org/10.1016/j.electacta.2019.134609.

[44] L. Nan, D. Xu, T. Gu, X. Song, K. Yang, Microbiological in fl uenced corrosion resistance characteristics of a 304L-Cu stainless steel against Escherichia coli, Mater. Sci. Eng. C. 48 (2015) 228-234. https://doi.org/10.1016/j.msec.2014.12.004.

[45] B. Tribollet, V. Vivier, M.E. Orazem, EIS technique in passivity studies: Determination of the dielectric properties of passive films, Elsevier Inc., 2018. https://doi.org/10.1016/B978-0-12-409547-2.13817-X.

[46] B. Hirschorn, M.E. Orazem, B. Tribollet, V. Vivier, I. Frateur, M. Musiani, Constant-Phase-Element Behavior Caused by Resistivity Distributions in Films, J. Electrochem. Soc. 157 (2010) C458. https://doi.org/10.1149/1.3499565.

[47] S. Zanna, A. Seyeux, A. Allion-Maurer, P. Marcus, Escherichia coli siderophoreinduced modification of passive films on stainless steel, Corros. Sci. 175 (2020) 108872. https://doi.org/10.1016/j.corsci.2020.108872.

[48] Wan Rafizah Wan Abdullah, N.A. Johari, N.F. Ibrahim, S. Rooshde, M. Sabri, M. Ghazali, Comparison of biocorrosion behavior of stainless steel $316 \mathrm{~L}$ and mild steel, Int. J. Mech. Eng. Technol. 10 (2019) 404-411. http://www.iaeme.com/ijmet/issues.asp?JType=IJMET\&VType=10\&IType=3 ISSN.

[49] M. Benoit, C. Bataillon, B. Gwinner, F. Miserque, M.E. Orazem, C.M. SánchezSánchez, B. Tribollet, V. Vivier, Comparison of different methods for measuring the passive film thickness on metals, Electrochim. Acta. 201 (2016) 340-347. https://doi.org/10.1016/j.electacta.2015.12.173.

[50] T. Barrès, B. Tribollet, O. Stephan, H. Montigaud, M. Boinet, Y. Cohin, 
1 Characterization of the porosity of silicon nitride thin layers by Electrochemical

2 Impedance Spectroscopy, Electrochim. Acta. 227 (2017) 1-6.

3 https://doi.org/10.1016/J.ELECTACTA.2017.01.008.

4 [51] T.T.M. Tran, B. Tribollet, E.M.M. Sutter, New insights into the cathodic dissolution of aluminium using electrochemical methods, Electrochim. Acta. 216 (2016) 58-67. https://doi.org/10.1016/J.ELECTACTA.2016.09.011.

[52] M.E. Orazem, B. Tribollet, Electrochemical Impedance Spectroscopy, John Wiley \& Sons, Inc., Hoboken, NJ, USA, 2017. https://doi.org/10.1002/9781119363682.

[53] A.M.P. Simões, M.G.S. Ferreira, B. Rondot, M. da C. Belo, Study of Passive Films Formed on AISI 304 Stainless Steel by Impedance Measurements and Photoelectrochemistry, J. Electrochem. Soc. 137 (1990) 82-87.

[54] I.D.A. Hamidah, A. Solehudin, A. Setiawan, A. Hamdani, M.A.S. Hidayat, F. Adityawarman, F. Khoirunnisa, A.B.D. Nandiyanto, Corrosion study of AISI 304 on $\mathrm{KOH}, \mathrm{NaOH}$, and $\mathrm{NaCl}$ solution as an electrode on electrolysis process, J. Eng. Sci. Technol. 13 (2018) 1345-1351.

16 

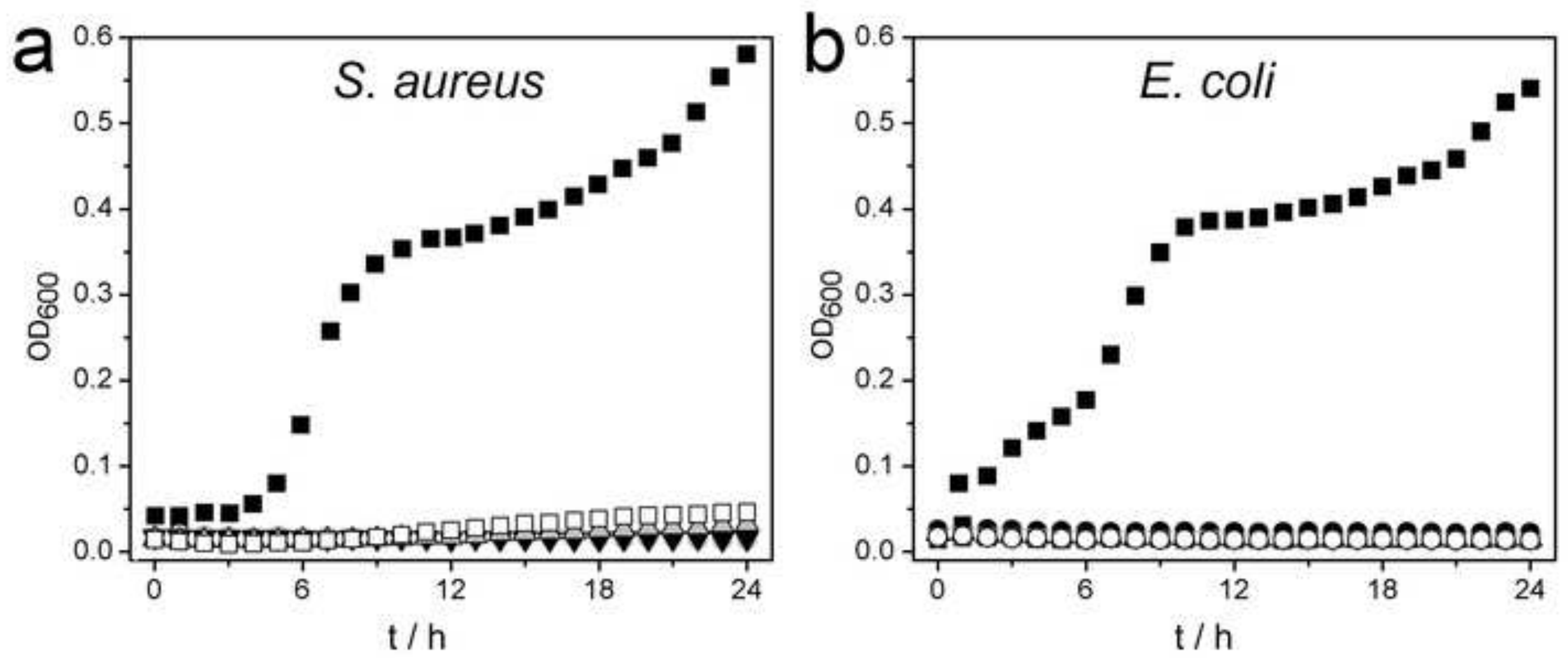


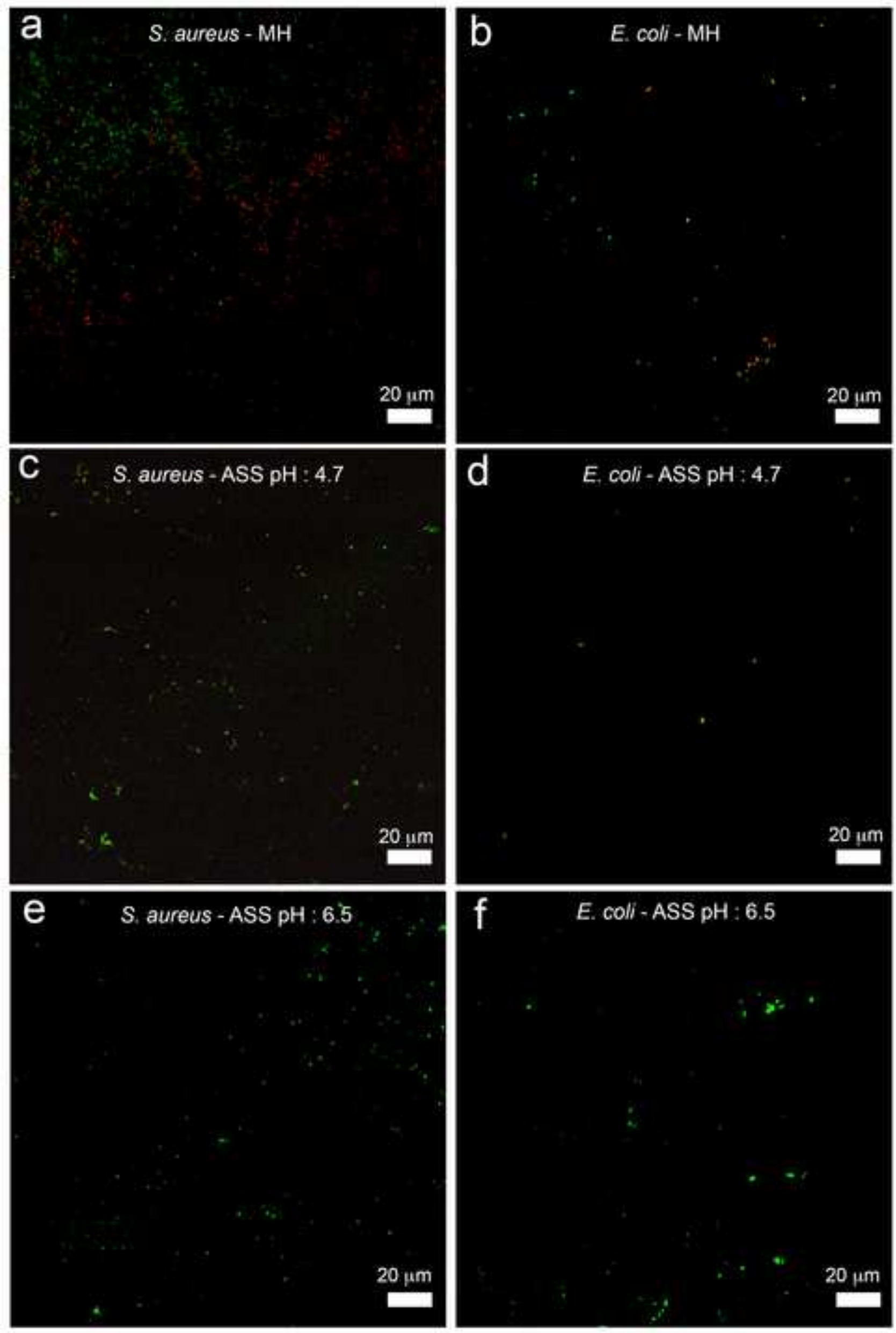



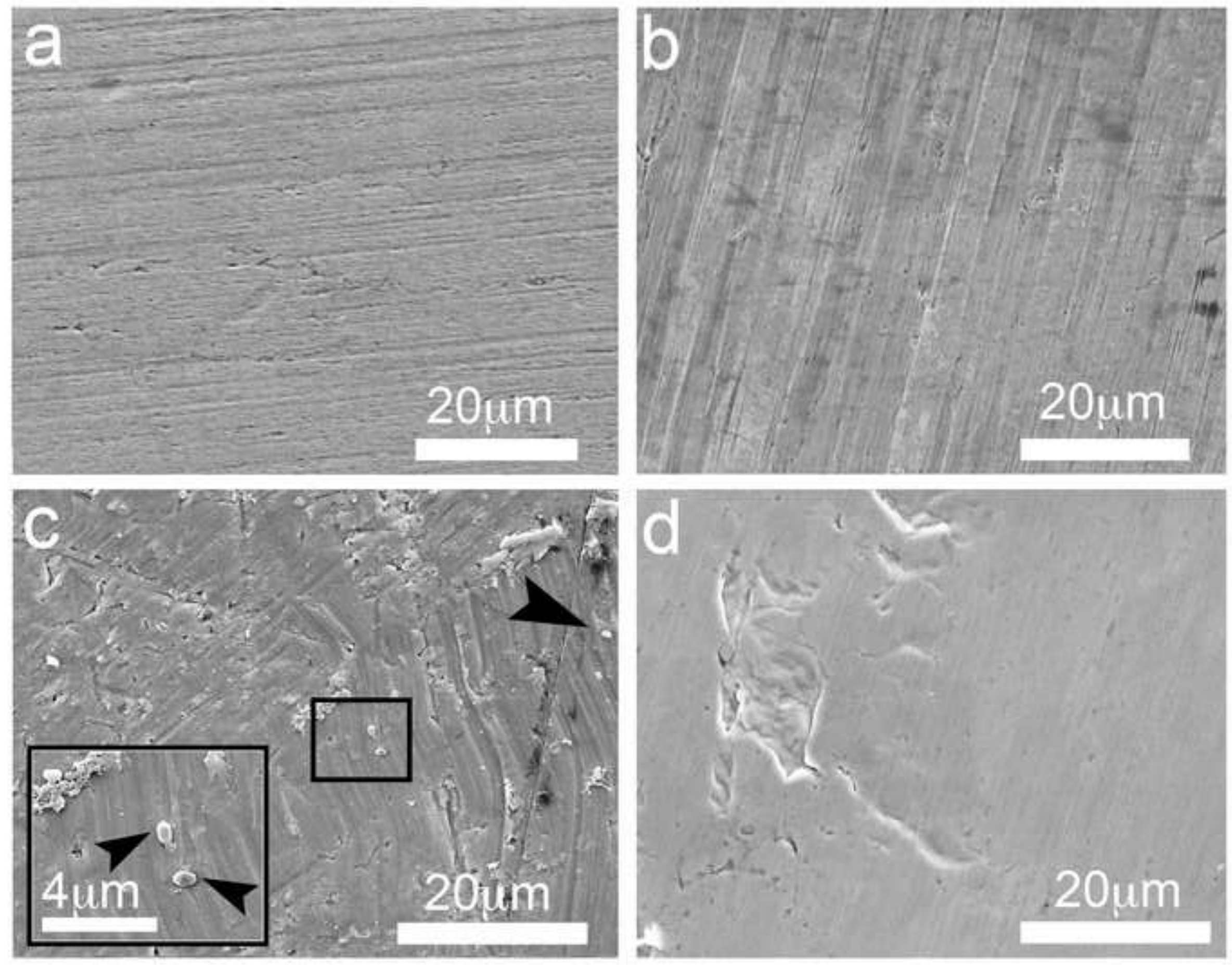

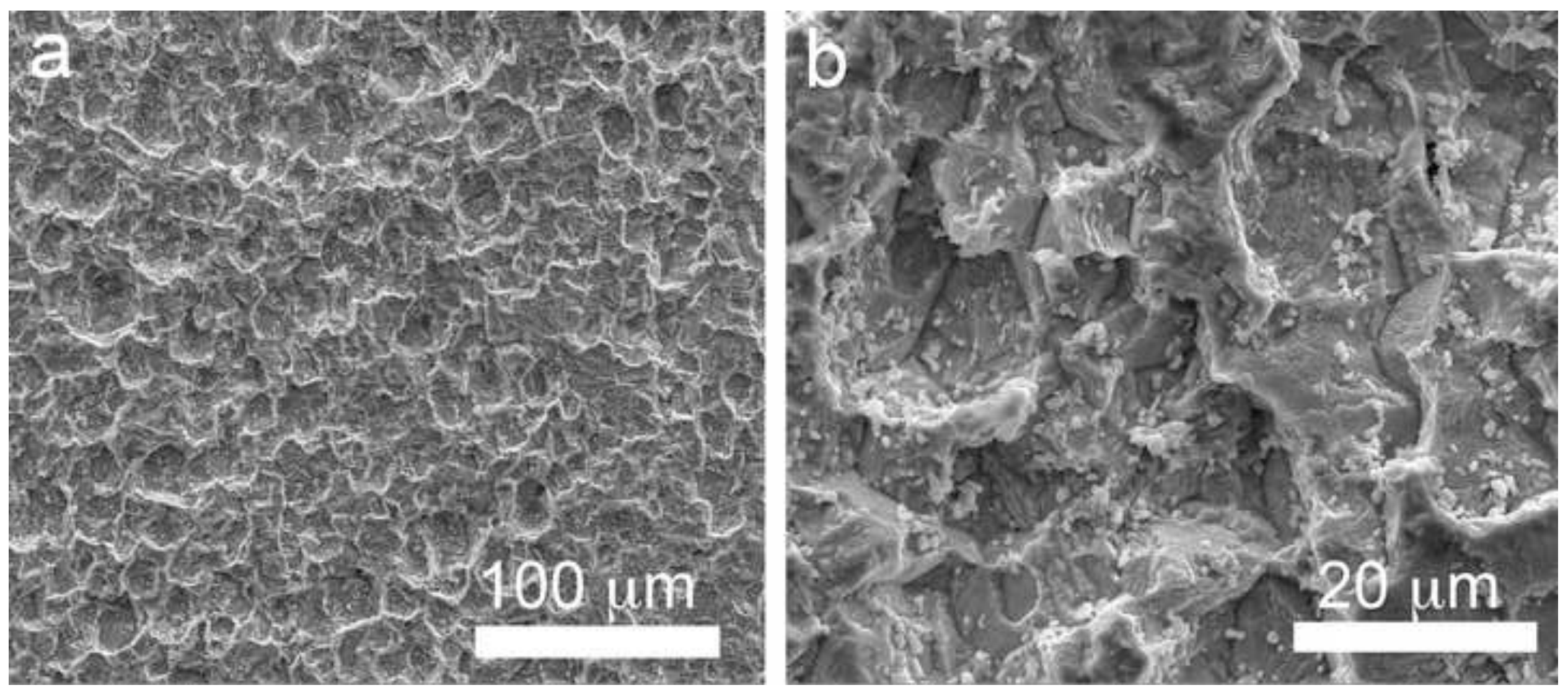

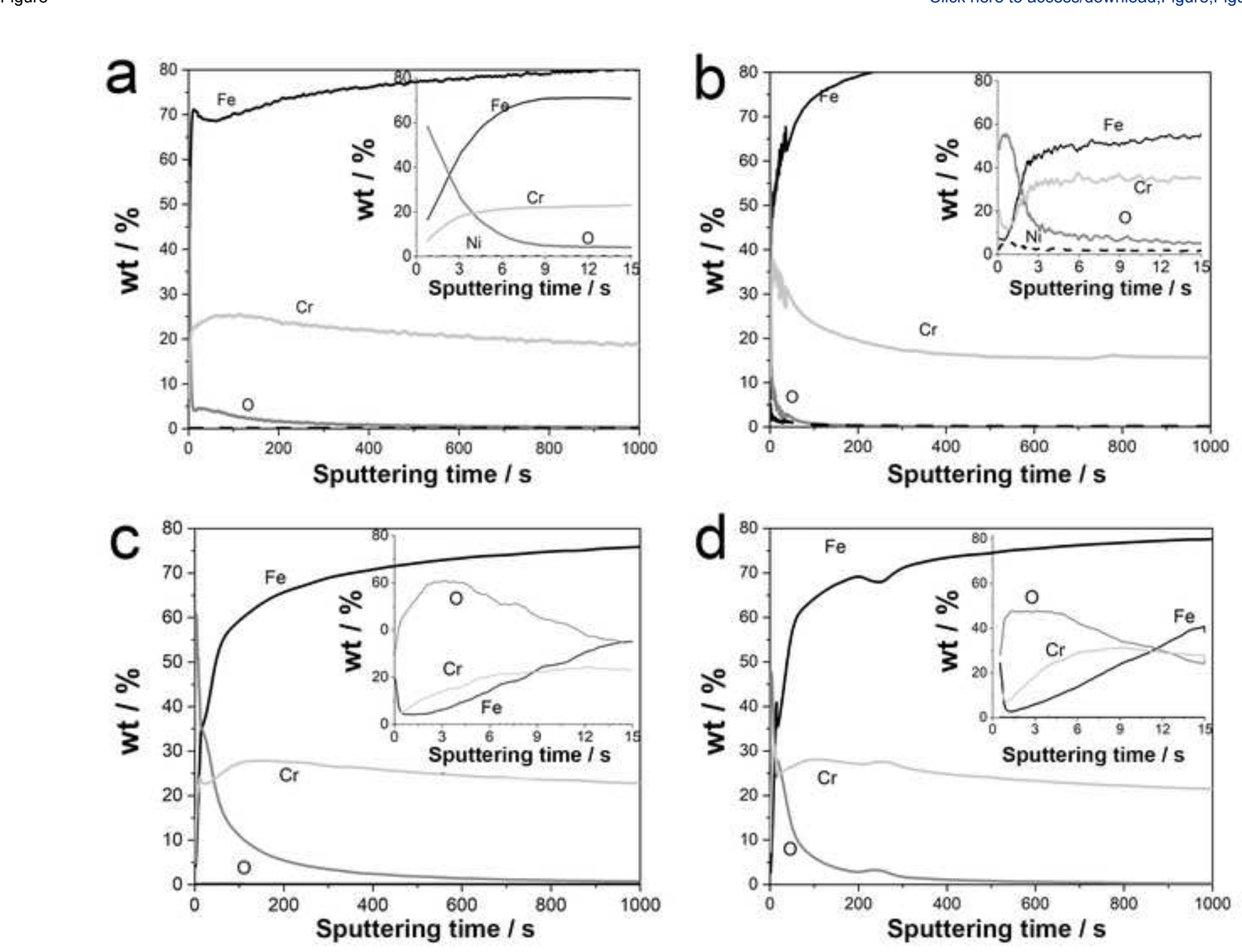

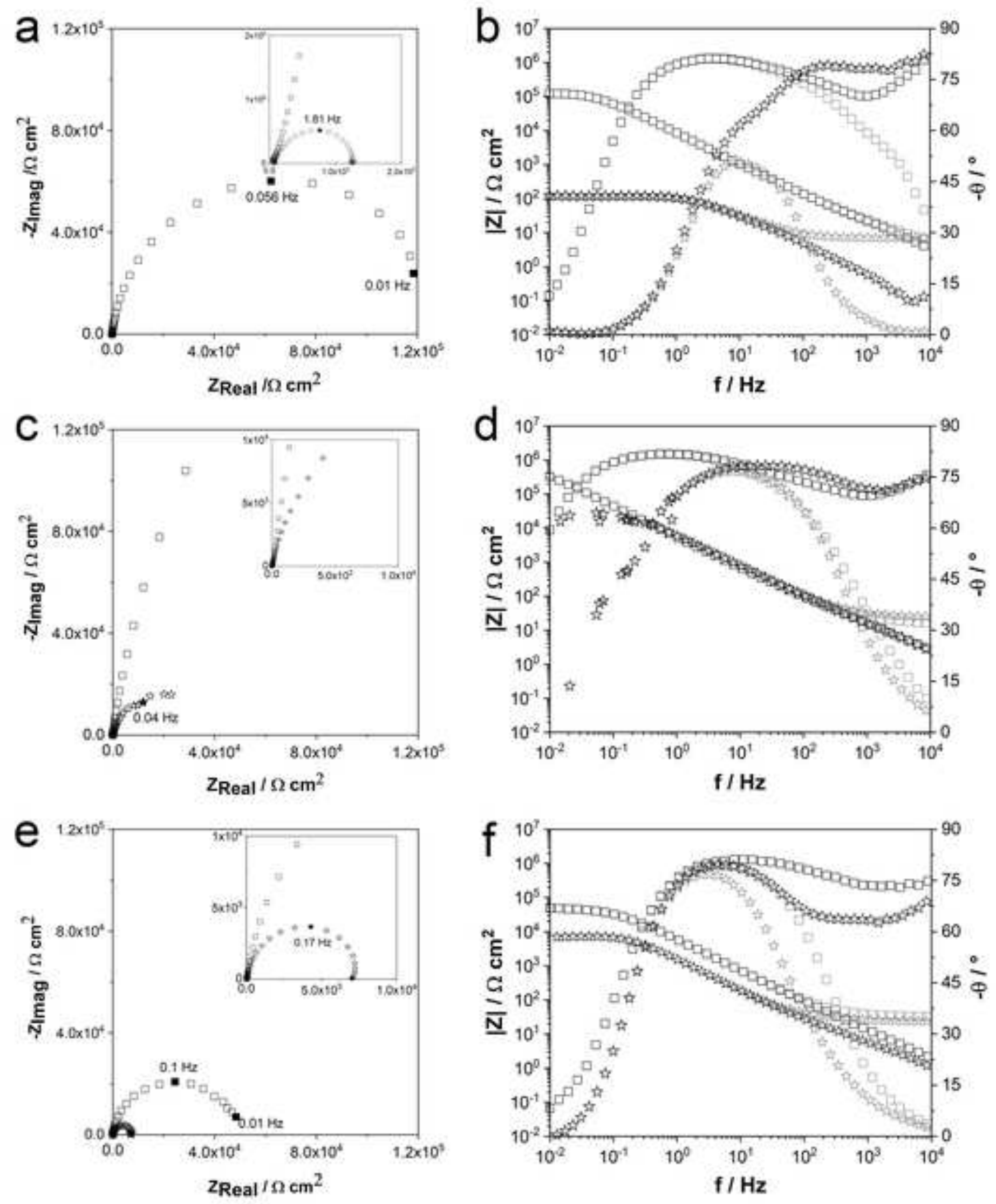

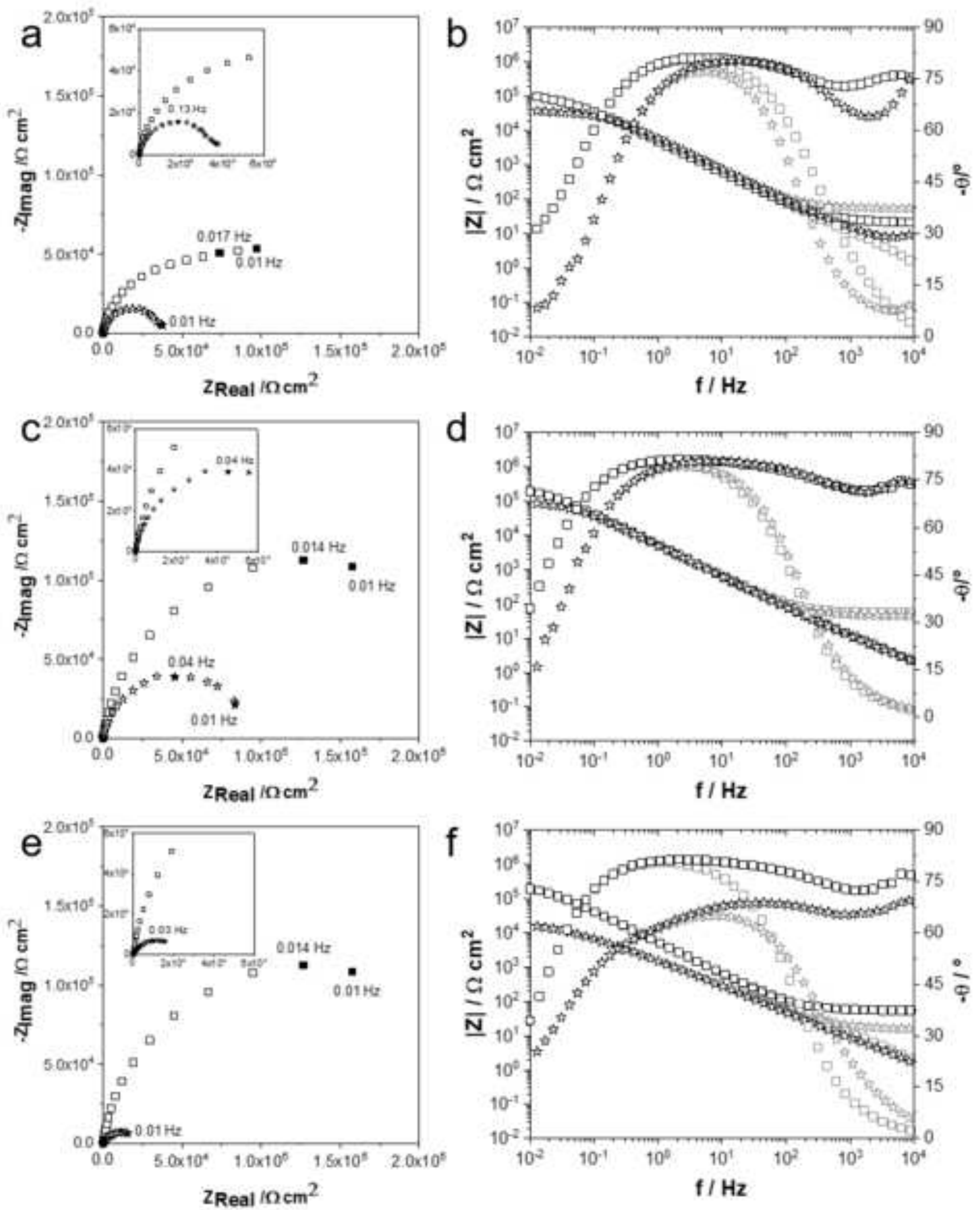
Click here to access/download;Figure;Figure 8.tif $\underline{\underline{ }}$
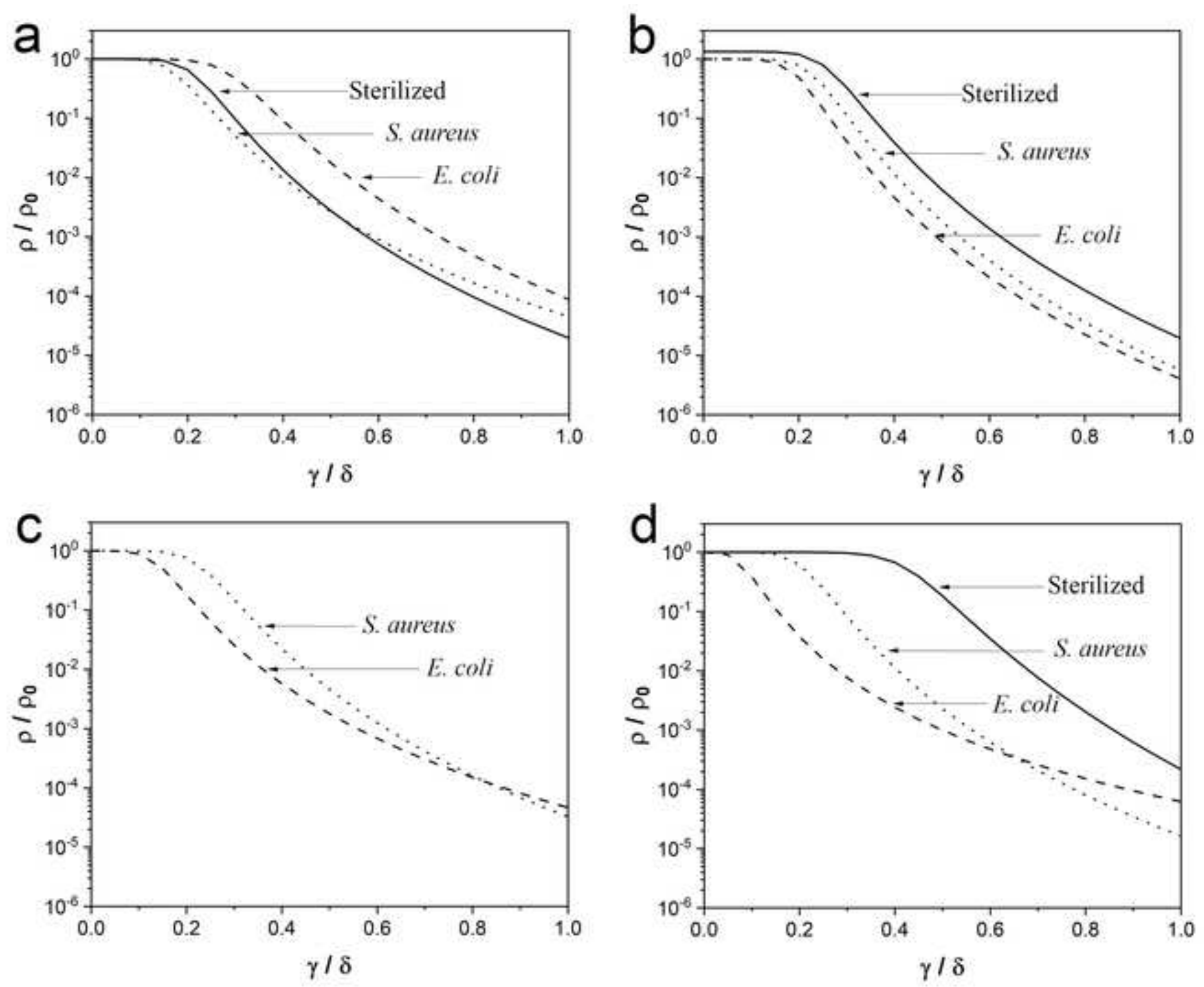

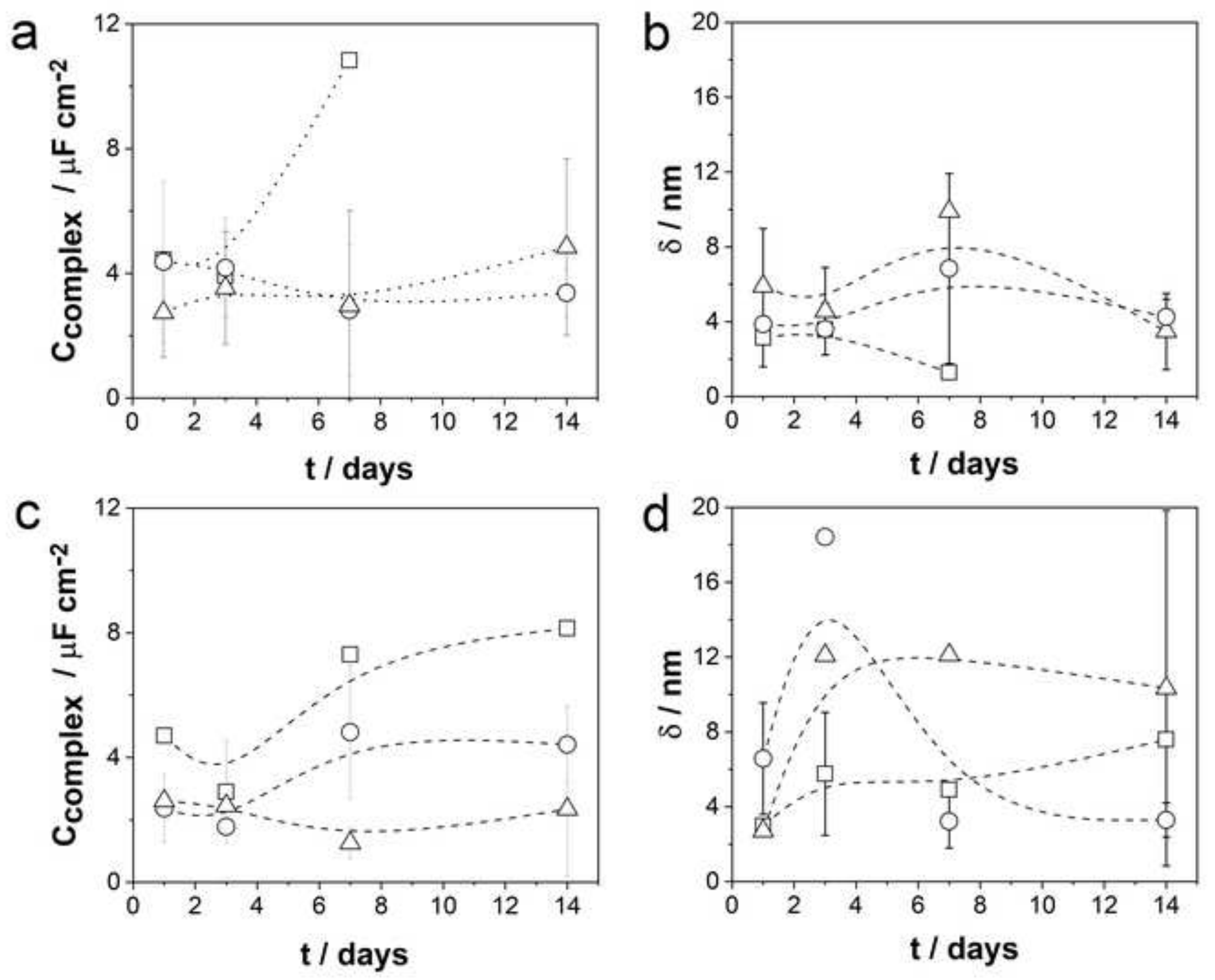

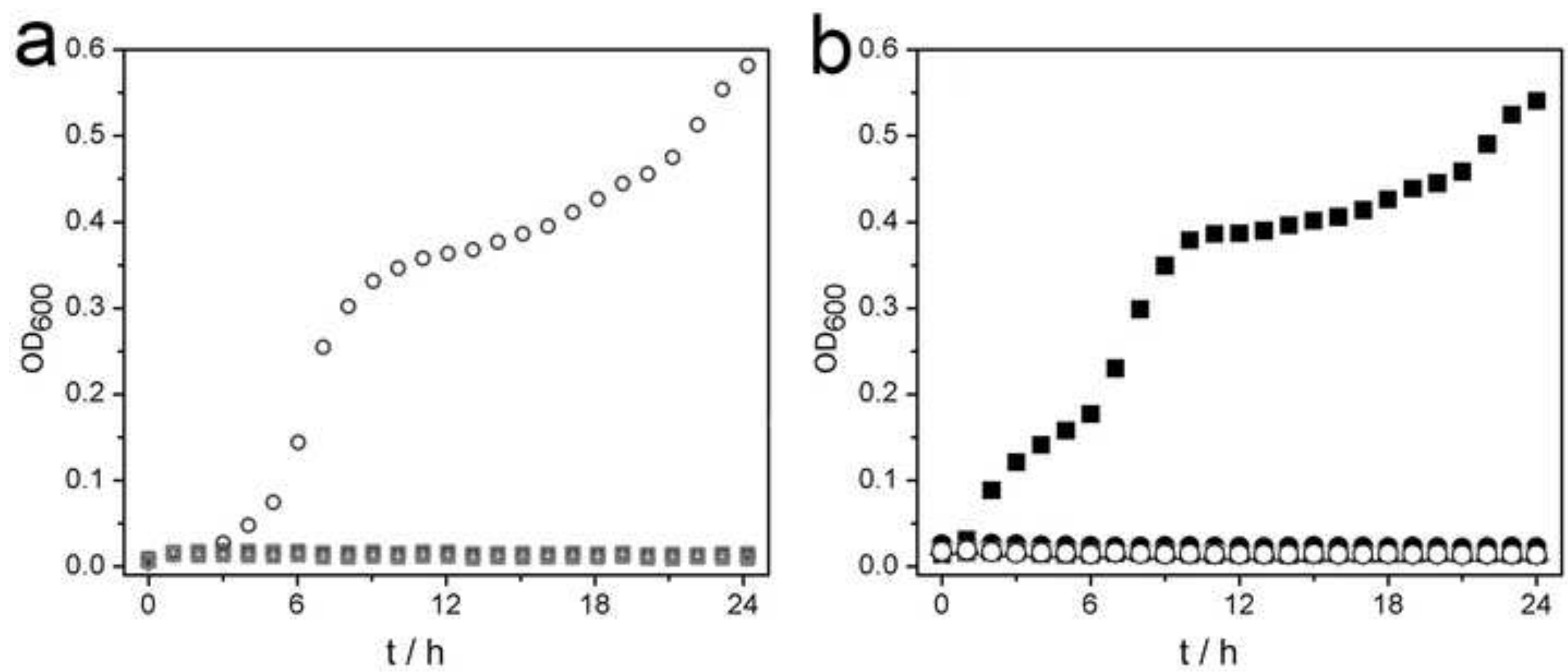

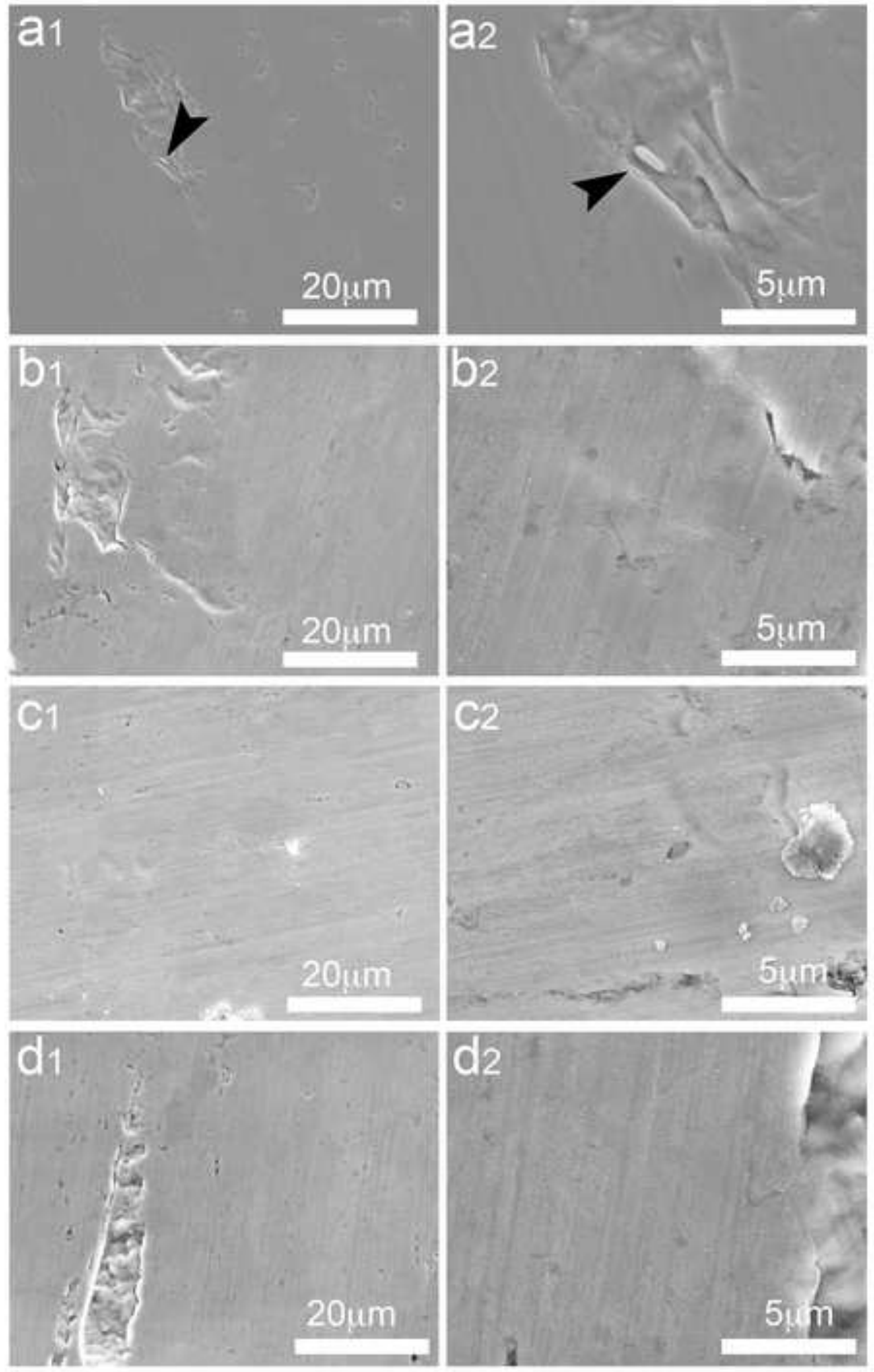

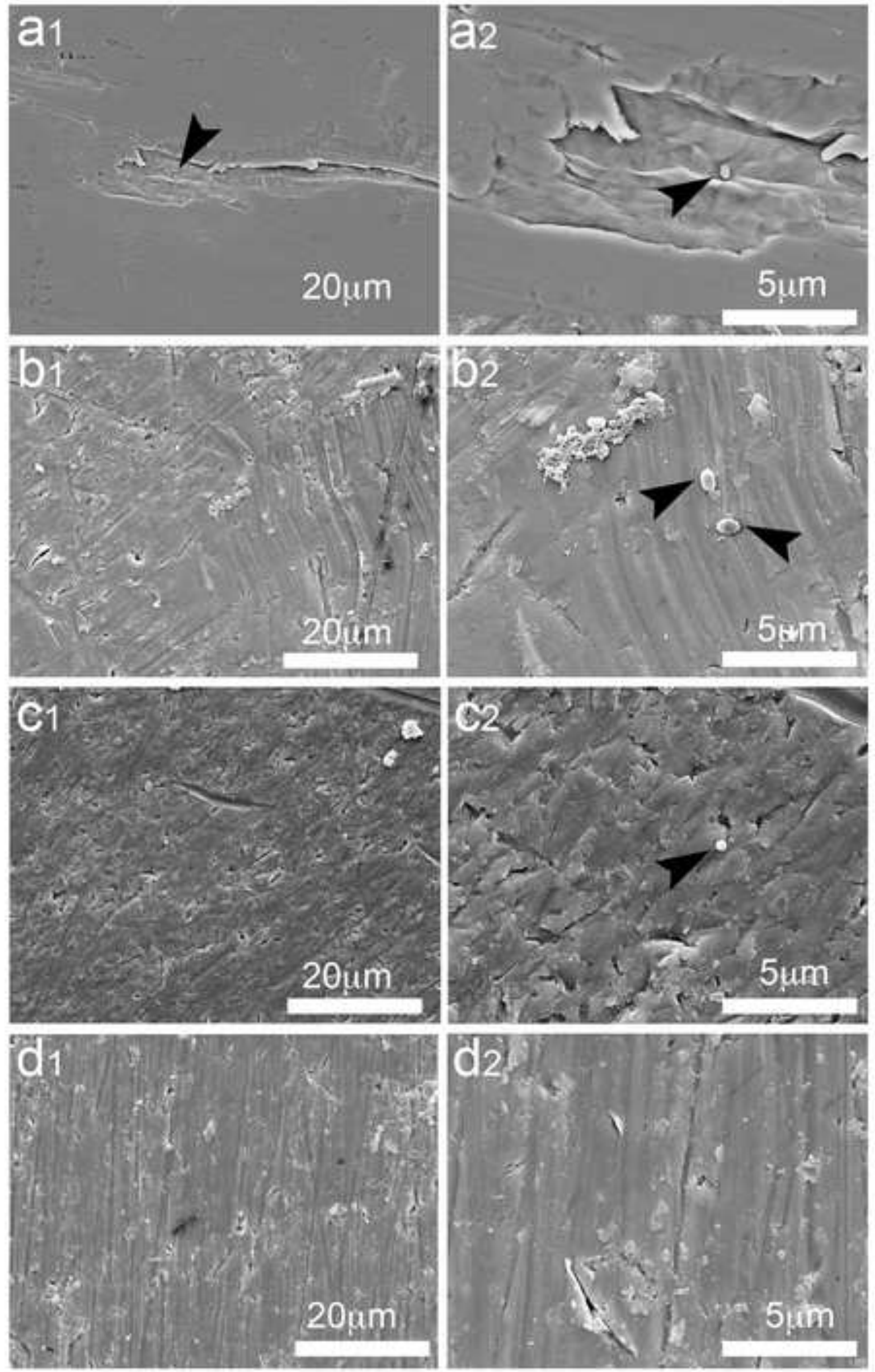

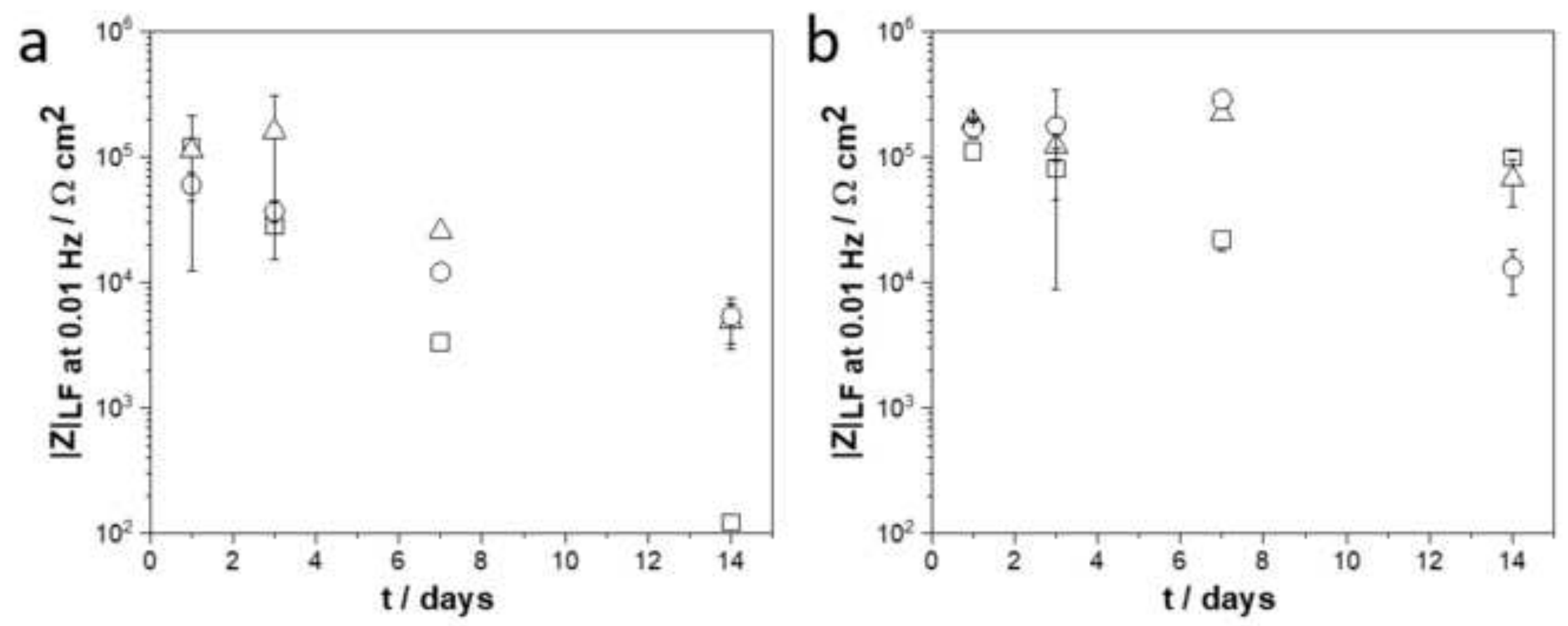

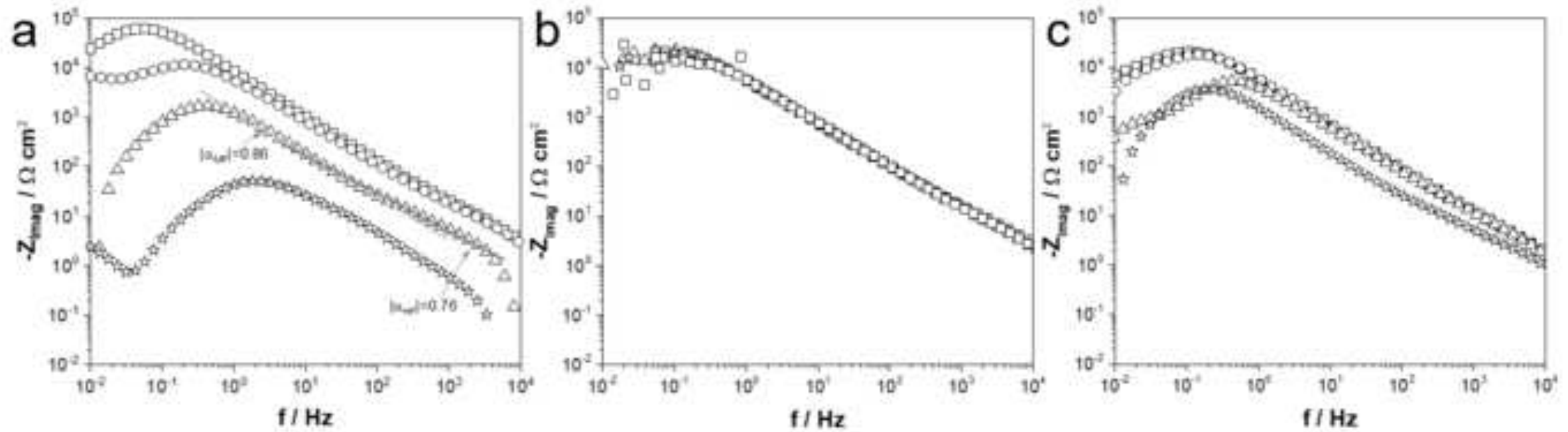


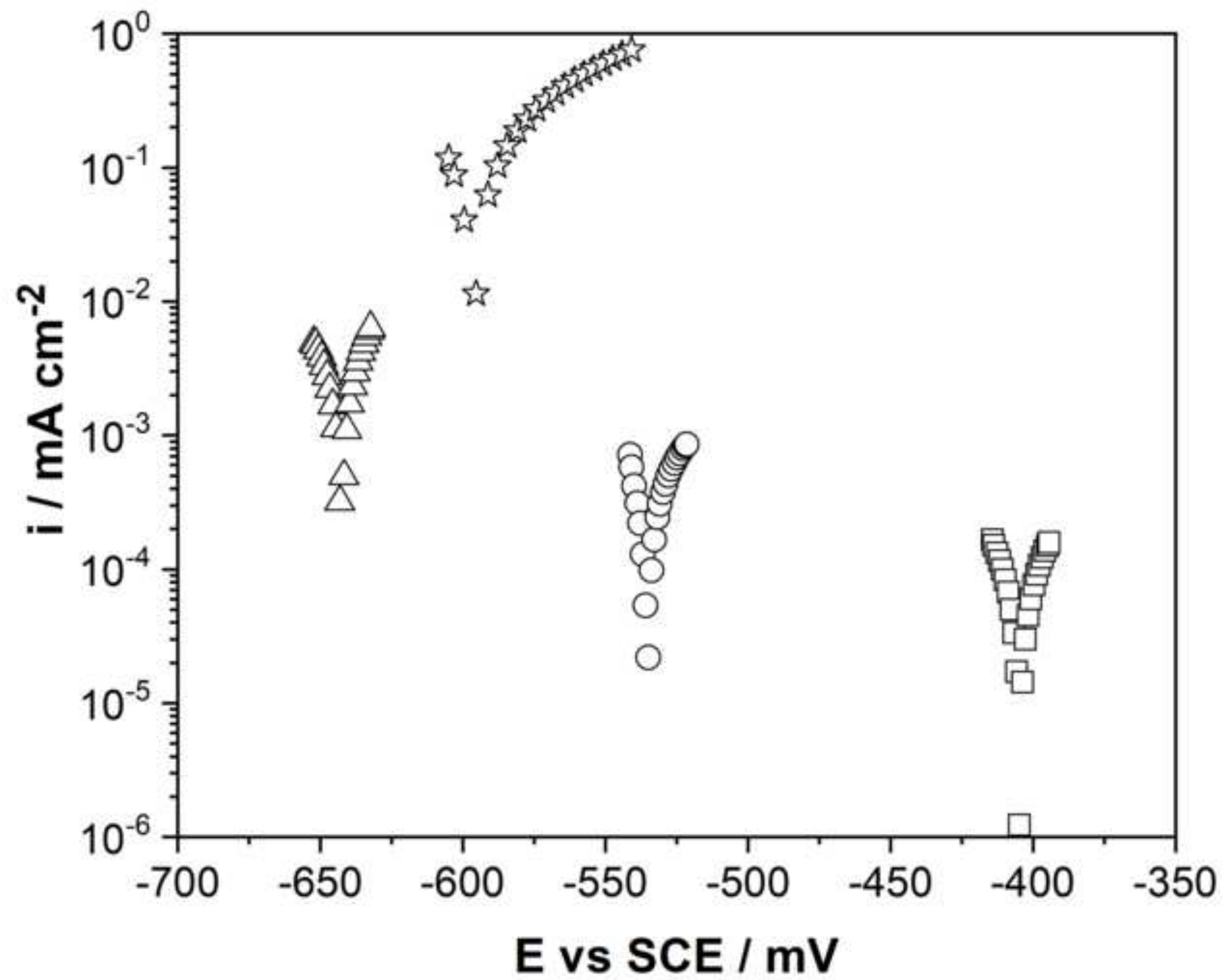


Click here to access/download RDM Data Profile XML DataProfile_5331359.xml 


\section{Declaration of interests}

$\square$ The authors declare that they have no known competing financial interests or personal relationships that could have appeared to influence the work reported in this paper.

$\square$ The authors declare the following financial interests/personal relationships which may be considered as potential competing interests:

Declarations of interest: none 


\section{Author statement}

Manuscript title: "Corrosion Analysis of Stainless Steel 430 in the presence of Escherichia coli and Staphylococcus aureus."

Authors: C. Guerra, A. Ringuedé, M. I. Azocar, M. Walter, C. Galarce, F. Bedioui, M. Cassir and M. Sancy

All persons who meet authorship criteria are listed as authors, and all authors certify that they have participated sufficiently in work to take public responsibility for the content, including participation in the concept, design, analysis, writing, or revision of the manuscript. Furthermore, each author certifies that this material or similar material has not been and will not be submitted to or published in any other publication before its appearance in the Corrosion Science.

\section{Authorship contributions}

Please indicate the specific contributions made by each author. The name of each author must appear at least once in each of the three categories below.

\section{Category 1}

- Conception and design of study: Mamié Sancy, Carolina Guerra, Manuel Ignacio Azócar and Armelle Ringuedé.

- $\quad$ Acquisition of data: Carolina Guerra, Mariana Walter, Carlos Galarce.

- Analysis and/or interpretation of data: Mamié Sancy, Carolina Guerra, Manuel Ignacio Azócar, Armelle Ringuedé.

\section{Category 2}

- $\quad$ Drafting the manuscript: Mamié Sancy, Carolina Guerra, Manuel Ignacio Azocar and Armelle Ringuedé.

- Revising the manuscript critically for important intellectual content: Armelle Ringuedé, Michel Cassir, Mamié Sancy, Fethi Bedioui, Manuel Ignacio Azocar and Carolina Guerra

\section{Category 3}

- $\quad$ Approval of the version of the manuscript to be published: All authors 
Click here to access/download Supplementary Material Supplementary file_20201127.pdf 